\title{
The Blood-Brain Barrier: Structure, Function and Therapeutic Approaches to Cross It
}

Marta Tajes ${ }^{\mathrm{a}}$, Eva Ramos-Fernández ${ }^{\mathrm{a}}$, Xian Weng-Jiang ${ }^{\mathrm{a}}$, Mònica Bosch-Morató ${ }^{\text {, }}$ Biuse Guivernau $^{\mathrm{a}}$, Abel Eraso ${ }^{\mathrm{a}}$, Bertrán Salvador ${ }^{\mathrm{a}}$, Xavier Fernàndez-Busquets ${ }^{\mathrm{b}, \mathrm{c}, \mathrm{d}}$, Jaume Roquer $^{\mathrm{e}}$ and Francisco J. Muñoz ${ }^{\mathrm{a} *}$

${ }^{a}$ Laboratory of Molecular Physiology and Channelopathies, Department of Experimental and Health Sciences, Universitat Pompeu Fabra (UPF), Barcelona, Catalonia, Spain; ${ }^{b}$ Nanomalaria Group, Institute for Bioengineering of Catalonia (IBEC), Barcelona; ${ }^{\mathrm{c} B a r c e l o n a}$ Centre for International Health Research (CRESIB, Hospital Clínic-Universitat de Barcelona); ${ }^{\mathrm{d}}$ Biomolecular Interactions Team, Nanoscience and Nanotechnology Institute (IN2UB), University of Barcelona; ${ }^{\text {e Servei }}$ de Neurologia, Hospital del Mar-IMIM, Barcelona.

*To whom correspondence should be addressed:

Dr. Francisco J. Muñoz

Laboratori de Fisiologia Molecular i Canalopaties

Departament de Ciències Experimentals i de la Salut

Universitat Pompeu Fabra

C/ Dr. Aiguader, 88, Barcelona 08003, Catalonia, Spain

Fax: +34 9331609 01; Phone: +34 933160852

e-mail: paco.munoz@upf.edu 


\begin{abstract}
Blood Brain Barrier (BBB) is constituted by a specialized vascular endothelium that interacts directly with astrocytes, neurons and perycites. It protects the brain from the molecules of the systemic circulation but it has to be overcome for the proper treatment of brain cancer, psychiatric disorders or neurodegenerative diseases, which are dramatically increasing as the population ages. In the present work we have revised the current knowledge on the cellular structure of the BBB and the different procedures utilized currently and those proposed to cross it. Chemical modifications of the drugs, such as increasing their lipophilicity, turn them more prone to be internalized in the brain. Other mechanisms are the use of molecular tools to bind the drugs such as small immunoglobulins, liposomes or nanoparticles that will act as Trojan Horses favouring the drug delivery in brain. This fusion of the classical pharmacology with nanotechnology has opened a wide field to many different approaches with promising results to hypothesise that $\mathrm{BBB}$ will not be a major problem for the new generation of neuroactive drugs. The present review provides an overview of all state-of-the-art of the BBB structure and function, as well as of the classic strategies and these appeared in recent years to deliver drugs into the brain for the treatment of CNS diseases.
\end{abstract}

Keywords: blood brain barrier; membrane transport; drug delivery 
Index

1. Introduction

2. BBB structure and physiology

\subsection{BBB structure}

2.1.1. Characteristics of the BBB ECs

2.1.2. The binding of the ECs

2.1.2.1. Tight Junctions

2.1.2.2. Adherens Junctions

2.1.3. Brain maintenance

\subsection{BBB Physiology}

2.2.1. The paracellular pathway

2.2.2. The transcellular pathway

2.2.2.1. Receptor-mediated transcytosis

2.2.2.2. The efflux transport system

2.2.2.3. Charged compound interaction

2.2.2.4. Carrier-mediated pathway

2.2.3. BBB disruption in pathophysiological conditions

3. In vitro $\mathrm{BBB}$ models in experimental research

4. CNS drug delivery

\subsection{Invasive techniques}

4.1.1. BBB modification

4.1.1.1. Hyperosmotic Shock

4.1.1.2. Biochemical disruption

4.1.1.3. AKGs

4.1.1.4. Ultrasound and electromagnetic radiation disruption 
4.1.2. Surgical approaches

4.1.2.1. Intracerebral administration

4.1.2.2. Intraventricular and intrathecal administration

4.1.2.3. Microchips

\subsection{Non-invasive techniques}

4.2.1. Medicinal chemistry approach

4.2.1.1. Chemical modification of the drug

4.2.1.2. Fusion proteins and Cell Penetrating Peptide

4.2.1.3. Drug delivery through microspheres and biodegradable wafers

4.2.2. Alternative methods

4.2.2.1. Intranasal administration

4.2.2.2. Molecular Trojan Horses

4.2.2.3. Genetic engineering

4.2.2.4. Liposomes, Nanoparticles and Solid Lipid Nanoparticles

4.2.2.4.1. Liposomes

4.2.2.4.2. Nanopolimers and nanoparticles

4.2.2.4.3. Solid lipid nanoparticles

4.2.2.4. Elimination and clearance of LP, NP and SNP

4.2.2.4.5. Targeted drug delivery

\section{Conclusions}

\section{Introduction}


The precise communication between neurons requires the isolation from the rest of the body achieved by the blood-brain barrier (BBB), a highly specialized structure composed by different cell types that controls the movement of molecules from each compartment to the other. However in pathological processes affecting to Central Nervous System (CNS) the BBB limits hardly the targeting and delivery of the drugs used in their treatment. Most of the adopted strategies are directed to bypass the BBB permitting the drugs to reach its target in the CNS and include invasive methods as direct injection or even transient $\mathrm{BBB}$ disruption but the benefits do not always overcome the risks (Begley, 2004). Therefore drug design based on medicinal chemistry has been adopted. This strategy consists of modifying the physicochemical properties of the drug to increase its permeability across the BBB and to improve its targeting to the CNS. Nowadays nanotechnology-based approaches are raising as a procedure to deliver drugs without worrying about the nature of the molecules since they usually encapsulate any molecule, which masks any limiting physicochemical deficiency (Vlieghe and Khrestchatisky, 2012). In order to facilitate CNS drug discovery, in vitro models could be implemented by using primary culture or cell lines that mimic BBB properties such as permeability, efflux pumps and high electrical resistance (Wolburg and Lippoldt, 2002).

\section{BBB structure and physiology}

Neurons need a constant supply of oxygen and nutrients being located no further than 8-20 $\mu \mathrm{m}$ of distance from capillaries (Schlageter et al, 1999) but brain homeostasis is critical and necessary because neurons are sensitive to many compounds and to subtle changes in their concentrations. To solve these requirements brain vessels are modified forming the BBB, a highly selective structural and biochemical barrier that maintains 
the intracerebral milieu supplying nutrients to the brain and protecting against environmental influences and harmful external agents.

\subsection{BBB structure}

Although brain capillaries are morphologically similar to those found in other tissues, brain vessels are functionally bound to the other cells of the brain parenchyma. BBB consists of blood vessels built up by specialized endothelial cells (ECs), astrocytes, pericytes, and neuronal terminations (Abbott and Romero, 1996; Abbott et al, 2006; Risau and Wolburg, 1990). Astrocytes lay their end-feet over the continuous basal lamina and form a very restrictive barrier (Abbott and Romero, 1996; Abbott et al, 2006) . Pericytes, a type of mesenchymal cell, occupy the perivascular space, between the capillary wall and astrocytes end-feet, except in the large vessels where smooth muscle cells replace them. Pericytes play a regulatory role in vasculature tone, stability, repairment and angiogenesis (Kutcher and Herman, 2009), as well as they can modulate astroglial function (Tamai and Tsuji, 2000; Thomas, 1999). Finally, neurons are also participating actively in this structure since neuronal terminations arrive to all cells forming the BBB (Hellstrom et al, 2001; Kacem et al, 1998) (Fig.1).

\subsubsection{Characteristics of the BBB ECs}

In order to achieve a more restrictive permeability, BBB ECs have specific characteristics compared to peripheral ECs: i) a lower number of endocytic vesicles, which limits the transcellular flux; ii) no fenestrations; iii) high electrical resistance due to tight junctions that restrict the amount of paracellular flux; iv) higher mitochondrial volume reflecting a high cell metabolism; and, v) specialized transport systems (Brightman and Kadota, 1992; Rubin and Staddon, 1999). ECs are surrounded by the 
basal lamina, produced by pericytes (Lai and Kuo, 2005), an extracellular matrix containing collagens, glycoproteins, laminins, proteoglycans and other proteins (Abbott et al, 2006). Brain microvasculature permeability is highly affected by modifications of the basal membrane (Sarna et al, 1979) as occurs in stroke or inflammation producing generally edema due to BBB disruption (Perry et al, 1997).

\subsubsection{The binding of the ECs}

At the subcellular level, the main components responsible for the structural integrity of the BBB are the tight junctions (TJ) and the adherens junctions (AJ). TJ seal the ECs forming a continuous tubular structure, while the AJ play a major role in the initiation and maintenance of EC contact. In peripheral ECs the TJ are placed apically and separated from AJ (Butt et al, 1990; Staddon and Rubin, 1996) but in BBB ECs they are close to each other (Schulze and Firth, 1993; Stamatovic et al, 2008), forming the junction complex between adjacent ECs. The junction complex consists of all the transmembrane proteins and accessory cytoplasmic proteins located on the apical side of the endothelium(Stamatovic et al, 2008). Transmembrane proteins interact directly inside the junctional complex, whereas cytoplasmic proteins serve as an anchor that binds the transmembrane proteins with the actin cytoskeleton (Petty and Lo, 2002). The high transendothelial electrical resistance in brain endothelium (TEER; $>2000 \mathrm{ohm} \mathrm{cm}{ }^{2}$ compared with 2-20 ohm $\mathrm{cm}^{2}$ resistance in peripheral capillaries) (Butt et al, 1990) is due to a better occlusion of the intercellular cleft by the TJ complex than in peripheral capillaries (Wolburg and Lippoldt, 2002). TJ integrity depends highly on intact AJ, where the cell-cell adhesion molecules are found.

\subsubsection{Tight Junctions}


Located in the upper part of the apical section of the plasma membrane, TJ constitute the first and the most important seal to prevent the paracellular diffusion of solutes, also participating in the lateral diffusion regulation between both apical and basolateral plasma membrane domains maintaining plasma membrane protein and lipid polarity (Brown and Stow, 1996; Gumbiner, 1987). They are composed of at least 3 major transmembrane proteins, claudin, which is exclusively located in TJ and have 4 membrane-spamming regions with two extracellular loops and two intracytoplasmic termini (Furuse et al, 1999; Gonzalez-Mariscal et al, 2000) occludin, a four transmembrane segment protein with two equal extracellular loops and three intracytoplasmic domains (Balda et al, 2000), and junctional adhesion molecules (JAMs), which belong to the immunoglobulin superfamily (Bazzoni and Dejana, 2004; Petty and Lo, 2002). They all share a single transmembrane domain and two large immunoglobulin-like loops (Williams et al, 1999). JAMs are also involved in the physiological function of the junctions related to monocyte extravasation (Palmeri et al, 2000) (Fig. 2 and Table 1).

Occludins bind to zonula occludens protein 1 (ZO-1) through its C-terminal domain in all types of endothelium (Furuse et al, 1999), but in brain endothelium ZO-1 distribution is more continuous (Hirase et al, 1997) and there is a higher occludin expression. However, such high levels are not sufficient to ensure high-resistance junctions, so other levels of control are necessary to determine junctional properties. There are reports suggesting that the state of phosphorylation of junctional proteins could be involved in their activity (Lampugnani et al, 1997; Maher and Pasquale, 1988; Risau and Wolburg, 1990; Sarna et al, 1979). Actually, preliminary experiments show that occludin is more highly phosphorylated in cultured brain ECs than in peripheral ECs (Rubin and Staddon, 1999). Also, other proteins like the catenin p120 and p100 can 
be phosphorylated under stimuli that affect TJ permeability (Ratcliffe et al, 1997; Schlageter et al, 1999).

The third major protein components of TJ are JAMs, which belong to the immunoglobulin superfamily (Bazzoni and Dejana, 2004). Beside these three major transmembrane proteins, there are some TJ accessory cytoplasmic proteins, distinguished by the presence or absence of a PDZ motif (Stamatovic et al, 2008) (Table 1). The PDZ motif is an $80-90$ amino acid sequence located in carboxyl terminal mediating interaction with other proteins. The majority of the proteins included in this group have multiple PDZ domains.

\subsubsection{Adherens Junctions}

$\mathrm{AJ}$ are essential in the maintenance of $\mathrm{TJ}$ and the junctional complex due to their role in keeping contiguous cells together. The main components of the AJ are transmembrane glycoproteins of the cadherin superfamily, mainly vascular endothelium cadherin (Ve-cadherin), that are able to form homotypic adhesive complexes with adjacent cells in the presence of $\mathrm{Ca}^{2+}$ (Petty and Lo, 2002). The glycoproteins are linked to the cytoskeleton through a cytoplasmic plaque by anchor proteins from the Armadillo superfamily such as $\alpha$-catenin, $\beta$-catenin, $\gamma$-catenin and $\mathrm{p} 120^{\mathrm{ctn}}$ (McCrea and Gumbiner, 1991; Nagafuchi and Takeichi, 1989). They all possess an Armadillo arm or repeat, which is a 42-aminoacid sequence that mediates binding to the cytoplasmic tail of the classical cadherins (Aono et al, 1999). A complex is formed between $\alpha-, \beta-$, and $\gamma$ catenin, which is linked to the actin cytoskeleton through $\alpha$-catenin (Lampugnani et al, 1995). Recently, a new catenin termed $\mathrm{p} 120^{\mathrm{ctn}}$ was discovered (Bazzoni, 2006). Its function is still unclear but it has been reported that it presents a high affinity binding to 
Ve-cadherin suggesting certain relevance in BBB permeability and function (Bazzoni, 2006; Hatzfeld, 2005).

\subsubsection{BBB maintenance}

Transplantation experiments showed that the microenvironment is important in the induction of brain EC cellular properties (Schulze and Firth, 1993; Stewart and Wiley, 1981), opening the research of factors that stimulate BBB formation.

Astrocytes play a key role in BBB creation and maintenance (Janzer and Raff, 1987; Wolburg and Lippoldt, 2002) since astrocyte end-feet contact directly endothelial cells in a netlike structure (Kacem et al, 1998; Stanness et al, 1997). These projections show specific features like a high density of orthogonal arrays of particles (OAPs). They contain the water channel aquaporin 4 (AQP4) and the Kir4.1K $\mathrm{K}^{+}$, which endow BBB with ion and volume regulation capability. The presence of these proteins in astrocytes correlates with the expression of agrin, an heparan sulphate proteoglycan, on the basal lamina (Verkman, 2002; Wolburg and Lippoldt, 2002). Agrin is involved in the integrity of $\mathrm{BBB}$ and accumulates in brain microvessels when $\mathrm{BBB}$ tightens. In vitro co-cultures of astrocytes and adult brain ECs achieve high electrical resistances, a strong evidence of the astrocyte effect in leading to tighter TJ (Dehouck et al, 1990; Hayashi et al, 1997; Isobe et al, 1996; Stanness et al, 1997). Astrocytes can regulate BBB characteristics, like the expression and polarized location of transporters such as P-glycoprotein (Perry et al, 1997; Schinkel, 1999) and GLUT1 (Abbott et al, 2006; McAllister et al, 2001), and of specialized enzyme systems such as $\gamma$-glutamyl transpeptidase ( $\gamma$-GTP) (Abbott, 2002; Haseloff et al, 2005; Hayashi et al, 1997; Sobue et al, 1999). 
The effect of astrocytes over ECs is exerted by the secretion of numerous signalling molecules, including cytokines such as IL-6, neurotrophins (Hawkins and Davis, 2005; Ridet et al, 1997), and factors including transforming growth factor- $\beta$ (TGF- $\beta$ ), glial-derived neurotrophic factor (GDNF) (Igarashi et al, 1999), basic fibroblast growth factor (bFGF) and angiopoetin1 (ANG1) (Lee et al, 2003). But ECs also exert an effect on astrocytes, enhancing their growth and differentiation through the endothelium-derived leukaemia inhibitory factor (LIF) (Mi et al, 2001). These signalling molecules will upregulate the endothelial enzyme $\gamma$ GTP (Mizuguchi et al, 1997), antioxidant enzymes in EC and astrocytes (Schroeter et al, 1999) and endothelial cAMP. Particularly cAMP produces an immediate elevation of TJ resistance via relaxation of the actin cytoskeleton (Brightman and Kadota, 1992; Rubin et al, 1991). cAMP affects the phosphorylation of myosin light chain, allowing a more lax reorganization of the actin cytoskeleton; the resulting weaker rearrangement of actin produces a strengthening of the cell-cell contacts (Goeckeler and Wysolmerski, 1995).

Pericytes have been also reported to participate in the growth and function of the endothelium (Hellstrom et al, 2001). Furthermore microglia is necessary for the integrity of the $\mathrm{BBB}$ and contributes in signalling and transcellular transport processes (Lee et al, 2001; Pardridge, 1992).

\subsection{BBB physiology}

Nutrients, ions and other molecules cross the BBB by paracellular diffusion through the junctional complex or by the transcellular pathway across the cells (Fig. 3).

\subsubsection{The paracellular pathway}


The paracellular pathway is a passive diffusion process that consists of the movement of lipophilic or low molecular mass solutes across the BBB, which depends on electrochemical, hydrostatic and osmotic gradient. This mechanism is structurally mediated by TJ and is solute concentration dependent. In terms of function, endothelial cytoskeleton contractility and adhesive forces drive the permeability of the junctional complex (Miller, 2002). A subtle and dynamic equilibrium between both forces determines one of the main blood-brain exchange processes. Nevertheless, the paracellular diffusion only plays a minor role in the brain-targeted drugs (Orthmann et al, 2011).

\subsubsection{The transcellular pathway}

The transcellular pathway, which can be energy or non-energy dependent, includes transcellular diffusion across both the luminal and the abluminal membrane of the capillary endothelium (Engelhardt and Sorokin, 2009), receptor-mediated transcytosis, efflux transport system, endocytosis of positively charged molecules and carrier-mediated transport (Orthmann et al, 2011).

\subsubsection{Receptor-mediated transcytosis}

It is the main mechanism used by brain ECs to uptake molecules such as hormones or high molecular mass proteins such as insulin, leptin, low density lipoproteins, transferrin and IGF across the BBB (Duffy and Pardridge, 1987; Holly and Perks, 2006). This pathway is an active transport pathway that depends on temperature and can be saturated (Scherrmann, 2002). Receptor-ligand recognition promotes the formation of coated pits that eventually engulf the ligand by formation of an endocytic vesicle. The second step consists of an endosomal fusion that dissociates the receptor 
from the ligand (Scherrmann, 2002) and release the content by exocytosis. However, not all vesicles successfully cross the BBB since some fuse with lysosomes and their content is lost due to low $\mathrm{pH}$ and enzyme-mediated hydrolysis (Broadwell et al, 1988). It has been proposed that this is a target pathway for CNS drug delivery because it is neither size limited nor lipophilicity dependent. In addition it is considered safe and effective due to its high specificity and the use of an entirely physiological mechanism.

\subsubsection{The efflux transport system}

It is an active transport process where distinct substrates are removed from the CNS and transferred to the systemic circulation in order to prevent the accumulation of compounds that have gone through the BBB (Loscher and Potschka, 2005; Newton, 2006). In certain situations, some drugs are able to overcome the BBB but they do not achieve therapeutically active concentrations because of efflux pumps that carry them from parenchyma to the luminal membrane and back to the systemic circulation.

The prototypic efflux transporter is the glycoprotein P (gp-P), a glycosylated member of the ATP-binding cassette $(\mathrm{ABC})$ transporters, expressed on the luminal membrane of the endothelial cells. The gp-P is included in the class of multidrug resistance receptors (MDRs) characterized for being an ATP-dependent remover of anticancer drugs, antibiotics, immune system suppressors or ionic channel modulators (Loscher and Potschka, 2005). On brain capillaries there is a high concentration of gp-P, where it plays a role in avoiding the accumulation of toxins or drugs in the brain, being essential to protect the neuron viability (Schinkel et al, 1994; Schinkel et al, 1996). However, there are other transporter classes that are expressed in brain such as monocarboxylate transporters (MCTs) and organic anion transporters/organic anion transporter polypeptides (OAT/OATPs) (Lee et al, 2001; Sun et al, 2003). The latter, in 
contrast with $\mathrm{ABC}$ transporters, are an example of energy independent exchangers. Since they are unable to hydrolyse ATP they cannot transport a drug against its concentration gradient. OAT/OATPs tend to work as exchangers rather than pumps by using ion or substrate gradients. Therefore, their transport is bidirectional and relies on the drug concentration on both sides of the BBB (Fricker and Miller, 2004).

\subsubsection{Charged compound interaction}

Positively charged substances such as cationized albumin and histone interact with negatively charged components of the EC membrane allowing the adsorptivemediated endocytosis to overcome the BBB (Kang and Pardridge, 1994; Pardridge, 1994). This biological pathway can be used to increase the delivery of conjugated drugs across the $\mathrm{BBB}$ as happen with $\beta$-endorphin conjugated to cationized albumin (Pardridge et al, 1990). The cationized proteins are obtained by increasing their isoelectric point from neutral to highly alkaline. This approach is also being tested with other proteins such as antibodies in order to be used as diagnostics, neuroimaging and as a treatment for mental diseases (Kang and Pardridge, 1994; Pardridge et al, 1990).

\subsubsection{Carrier-mediated pathway}

The carrier-mediated pathway is a saturable transport process that can be energy dependent or independent, which mediates the exchange of substances between the systemic circulation and the brain parenchyma (Brasnjevic et al, 2009). These carriers are usually polarized and localized on both the luminal and abluminal membrane (Farrell and Pardridge, 1991). There are many carrier systems expressed in brain ECs in order to selectively vehicle a lot of molecules (Tamai and Tsuji, 2000), e.g. glucose is passively supplied through the GLUT-1 transporter by concentration gradient (Betz et 
al, 1983). In the case of amino acid, there are different and selective energy dependent carrier proteins, and it depends on the physicochemical properties of each amino acid. Large, neutral and aromatic amino acids are uptaken by the N- or L- system while small, neutral amino acids go through the A-system (Cancilla and DeBault, 1983; Pardridge and Oldendorf, 1975), the ASC system is responsible for the transport of sulphur-containing amino acids being the major transporter of cysteines. Finally, charged amino acids use ion channels, $\mathrm{Na} / \mathrm{K}$ pumps or $\mathrm{Na} / \mathrm{Cl}$ cotransporters (Mann et al, 2003).

\subsubsection{BBB disruption in pathophysiological conditions}

Under physiological conditions the junctional complex in the neurovascular system acts as a barrier that impairs the access of molecules and immune cells including monocytes, lymphocytes and other leukocytes. In a wide number of pathologies affecting the CNS, including infections or secondary inflammation, the integrity of the BBB is highly compromised and major membrane permeability changes occur: brain microvessels become more leaky and fluid extravasation generally produces brain oedema (Stamatovic et al, 2008).

This process is triggered by several groups of molecules: vasoactive agents such as histamine, substance $\mathrm{P}$, endothelin-1 and bradikinin, growth factors including basic fibroblast growth factor and transforming growth factor $\beta$, and other inflammatory mediators such as cytokines, matrix metalloproteases, free radicals and lipids (Stamatovic et al, 2008). One of the most severe complications associated with Plasmodium falciparum infection is cerebral malaria $(\mathrm{CM})$, which is due to the breakdown of the BBB (Adams et al, 2002) probably because of the action of cytokines such as TNF- $\alpha$ (Grau et al, 1989; Kwiatkowski, 1990). In ischemia and angiopathies 
BBB hyperpermeability and transient disruption can occur by action of thrombin, amyloid $\beta$-peptide, intracellular $\mathrm{Ca}^{2+}$ and immune system cells (Brown et al, 2004; Lee et al, 1997; Mackic et al, 1998). All these molecules and cell transendothelial migration alter the molecular distribution of the junctional complex, involving ZO-1 and occludin degradation, and actin cytoskeleton reorganization (Neuwelt, 2004). Adhesion molecules are responsible for the intracellular signalling that triggers functional changes in the endothelium. Brain ECs undergo modifications in surface protein expression, alteration in secretory function, reduced transendothelial electric resistance and increased leukocyte transmigration (Burns et al, 2000; Burns et al, 1997). These responses are mainly executed, after environmental changes, through cytoskeletal redistribution, junctional protein phosphorylation and alterations in calcium homeostasis (Couraud, 1998).

\section{In vitro BBB models in experimental research}

The use of purified bovine, rat, porcine and human brain endothelial cells and several immortalized cell lines have been employed to develop in vitro BBB models (Reinhardt and Gloor, 1997) as an alternative to in vivo models with animals. The in vitro assays raise less bioethical concerns than in vivo models and offer a more controlled experimental system as well as they produce significant economical savings.

The in vitro model must reproduce functional and structural BBB properties. and, therefore, has to preserve endothelial cell morphology with high expression of junctional proteins, selective permeability, expression of efflux transporters and maintenance of a high TEER as a marker of BBB maturity and integrity (Booth and Kim, 2012).

They can vary widely in complexity ranging from simple monolayers of cells to co-cultures of endothelial cells with slices of cortical tissue. Moreover the co-cultures 
that closely mimic the in vivo situation are those performed by culturing brain capillary endothelial cells on one side of a filter and astrocytes on the other.

Several barrier models employ cell lines that are not even of brain origin, such as Madin-Darby canine kidney, Caco-2 cell line from human colon carcinoma and ECV304, a cell line with mixed characteristics from endothelium and epithelium (Prieto et al, 2004). Although positive results have been achieved for passive diffusion assays, these cells that are not derived from brain endothelium may lack specific transporters or metabolic pathways (Polli, 2000). Currently, cultures of brain ECs are used to assay drug neurotoxicity and barrier permeability but the method is limited due to slow cell growth and easy contamination by other cell types (Brown et al, 2007). Up to date, rat brain EC monolayer culture is the simplest in vitro cell screening experiment and has proved to be useful in early stages of drug development (Garberg et al, 2005). However, co-culture models have demonstrated to be more suitable since their permeability is more selective (Reinhardt and Gloor, 1997). Two main approaches are available to obtain BBB-inducing brain capillary ECs (BCECs), the co-culture of BCECs with glial cells or the culture of BCECs in medium from glial and endothelial co-culture.

A pathological in vitro model resembling a drug resistant epileptic BBB has been developed as an alternative approach to assess drug permeability in vitro (Cucullo et al, 2007). The model was based on a primary cell culture obtained by biopsy of an epileptic patient that had undergone surgical intervention. The general aim of using pathological models of BBB is to screen drugs that may have different permeability due to disease-altered $\mathrm{BBB}$. Other alternatives to in vitro studies being considered use microfluidic in vitro models of BBB (Booth and Kim, 2012), and cells derived from invertebrates such as Drosophila melanogaster and Locusta migratoria or from zebrafish (Geldenhuys et al, 2012). In the particular case of the above mentioned 
cerebral malaria, primary cultures of porcine brain capillary endothelial cells have been used as in vitro BBB model (Treeratanapiboon et al, 2005).

\section{CNS drug delivery}

There are many drugs that could have a therapeutic effect in CNS pathologies but their application is limited due to their pharmacokinetics. There are different strategies to cross or to by-pass the $\mathrm{BBB}$ that can be grouped as invasive and noninvasive techniques (Figs. 4 and 5).

\subsection{Invasive techniques}

\subsubsection{BBB modification}

Brain endothelial junctional complexes avoid the access of drugs through the paracellular pathway. Modification of the BBB permeability can disrupt the junctional complexes and increase drug uptake in brain in a transient and reversible manner, avoiding an extended opening of the barrier which would lead to neurophatological changes, cerebral vasculopathy and seizures (Miller, 2002). This strategy apply to ensure the delivery of drugs into the brain parenchyma (Loch-Neckel and Koepp, 2010). This approach has several drawbacks such as diminished control of drug release and targeting and increased access of potentially toxic molecules. Nevertheless four methods are available to open the BBB: osmotic, biochemical, alkylglycerols (AKG) or ultrasound.

\subsubsection{Hyperosmotic Shock}


Hyperosmotic shock can be used to open the junctional complexes temporarily and reversibly to increase drug permeability. It is carried out by the infusion of highly concentrated saccharide solutions into the carotidal artery to reach the CNS (Kroll and Neuwelt, 1998). Brain ECs shrink under hypertonic environment due to the osmotic pressure that forces the water to exit. When the cells decrease in volume, small holes are generated at the tight junctions that permit the access of water-soluble drugs (Greenwood et al, 1988). In anticancer therapy, mannitol is being employed as a hyperosmolar agent to facilitate the delivery of cyclophosphamide, procarbazine and methotrexate (Doolittle et al, 1998). However, it has been reported that hypertonic infusion of mannitol in rat brain produced neuronal damage, alteration in glucose uptake, expression of heat shock proteins and microembolisms (Salahuddin et al, 1988).

\subsubsection{Biochemical disruption}

In vivo and in vitro studies of $\mathrm{BBB}$ pathological conditions have demonstrated that many vasoactive agents such as histamine, bradykinin and other molecules such as solvents, stabilizers or adjuvants increase BBB permeability (Matsukado et al, 1996). The signalling pathway of these molecules generally converges to the phosphorylation/dephosphorylation of the junctional complex proteins (Stamatovic et al, 2008). These biochemical changes in protein phosphorylation relax the cell-cell contact facilitating paracellular drug access. Alkermes Incorporation developed a synthetic bradykinin analog, Cereport (RMP-7), that increases cyclic GMP levels through binding to the cerebrovascular bradykinin B2 receptor, transiently disrupts the tight junctions in brain endothelial cells, and increases brain permeability (Bartus et al. 2000; Emerich et al. 2000). Furthermore, polysorbate 80 (PS80) - coated PBCA-NPs concentration-dependent, triggers the reversible opening of the BBB after 3-4 h (Rempe 
et al. 2011). The BBB is regenerated after 6- $10 \mathrm{~h}$ accompanied by normalized cell morphology and probably supported by an upregulation of claudin-5 (Hwang et al, 2013).

\subsubsection{AKGs}

Recent studies with anticancer agents have been carried out in a rat glioma tumour model after systemic administration of various AKGs (Erdlenbruch et al, 2003). The result was an increased delivery of the drug to the site comparable to the levels of drug uptake after hyperosmotic shock and far greater than upon biochemical disruption (Erdlenbruch et al, 2003). However, the mechanism involved in AKG function is not yet understood but many clues reveal a possible interaction with receptor located in the endothelium. This hypothesis is based on the knowledge that the barrier disruption is concentration and structure dependent, typical of receptor-mediated responses and it has been demonstrated that the alkyl group length and the number of glycerols determine the degree of BBB disruption (Patel et al, 2009).

\subsubsection{Ultrasound and electromagnetic radiation disruption}

Ultrasounds are able to specifically open local BBB regions, in contrast to the methods mentioned above. Two different, transient and reversible approaches are available to improve drug uptake: thermal, which induces a mild hyperthermia (Cho et al, 2002) and non-thermal, based on physical cavitation of the membrane (Vykhodtseva et al, 2008). Since hyperthermia has proved to increase membrane permeability, thermal site-directed opening of the BBB is contemplated as a possible strategy to enhance CNS drug delivery (Cho et al, 2002). The advantage of this technique is that it is site-specific 
and thus diminishes the risks inherent to a generalized BBB opening (Madsen and Hirschberg, 2010).

\subsubsection{Surgical approaches}

Direct local drug infusion is considered one of the simplest methods of brain drug delivery and is commonly used in emergency situations where the agent must reach urgently the brain, but there is a limitation due to the slow diffusion coefficient of the drugs. Drug diffusion depends on the location of the drug administration, liposolubility, molecular mass, polarity and tissue affinity. There are different pathways of direct injection: to the brain parenchyma by intracerebral implant or into the CSF via intraventricular infusion or intrathecal administration.

\subsubsection{Intracerebral administration}

This strategy has proved to be inefficient and clinically limited. In addition to the obvious need of surgical intervention, drug diffusion is strictly dependent on molecular mass and drug concentration in brain parenchyma is limited by rapid cerebrospinal fluid (CSF) exchange. Intracerebral administration would only be useful if the target sites were adjacent to the ventricles or on the parenchyma surface (Brasnjevic et al, 2009; Scheld, 1989).

\subsubsection{Intraventricular and intrathecal administration}

Intrathecal or intraventricular administration consists of a direct delivery of drug to the CSF bypassing the $\mathrm{BBB}$ and blood-CSF barrier. The procedure can be done by direct injection piercing the skull and into the ventricles or through lumbar puncture, both of them with a considerable associated risk. The ventricular system is connected 
with the brain parenchyma and thus any compound dissolved in the CSF will be able to diffuse and reach nearby CNS structures. Theoretically, solutes in the CSF are freely transported into the brain but experimentally not many successful results have been obtained (Blasberg et al, 1975). This is because physiologically the CSF tends to move in a direction opposite to that of the drug infusion. In addition, CSF replacement is done in a few hours needing a quick and continuous infusion of drugs with controlled extended release devices or formulations (Patel et al, 2009).

\subsubsection{Microchips}

Microchip delivery of drugs by implanting solid-state electronic silicon devices into the brain has been proposed as a way to deliver precise quantities of drugs under specific physiological conditions (Santini et al, 1999). There are studies for the brain tumors treatment using a micro-electro-mechanical systems (MEMS) technology to deliver drugs with precise temporal control over release kinetics. The device is a liquid crystalline polymer reservoir, capped by a MEMS microchip (Masi et al., 2012). And also resorbable, a multi-reservoir polymer microchip drug delivery system has been tested against a tumor model (Kim et al., 2007).

\subsection{Non-invasive techniques}

\subsubsection{Medicinal chemistry approach}

\subsubsection{Chemical modification of the drug}

Chemical modification in drug design is a widely used approach to ameliorate physicochemical properties of the compound in order to achieve expected pharmacokinetics. It consists of an active compound, the parent drug, which is 
reversibly modified to generate the prodrug. Once the prodrug reaches the target site in vivo the parent drug is released by chemical or enzymatic cleavage and then, exerts its biological effect (Ettmayer et al, 2004; Rautio et al, 2008). The general strategy to generate prodrugs is to increase the molecule lipophilicity or to reduce the ability to bind hydrogen (Patel et al, 2009). It is carried out attaching lipophilic moieties to the molecules and often to the polar functional groups since these are limiting factors of BBB permeability. The outcome of these chemical modifications usually increases the uptake in brain, although increased lipophilicity also implies higher uptake in peripheral tissues (Witt et al, 2001). For instance, to have a leptin capable of penetrating the BBB made a fusion protein; Tat-modified leptin is more accessible to hypothalamus through BBB with a significant inhibition of body-weight gain in high-fat-diet fed mice (Zhang et al., 2010).

\subsubsection{Fusion proteins or cell penetrating peptides}

Cell penetrating peptides (CPP) are short amphipathic cationic peptides that facilitate rapid internalization of exogenous cargo like proteins nucleic acids, liposomes, or nanoparticles (Sharma et al., 2013; Lalatsa et al. , 2014). It is not very well known the mechanism by which these peptides can cross the cell membrane. One of the first CPP described was the transactivator of transcription (TAT) from human immunodeficiency virus (HIV-1), followed by other natural CPPs (AntP/Penetratin), the Syn B vectors (family of vectors derived from the antimicrobial peptide protegrin 1) (Lalatsa et al. , 2014) or synthetic origin (Mastoparan/transportan) (Sharma et al., 2013).

TAT is a peptide which contains a basic region of six arginine and two lysine residues. These basic amino acids seem to be the key to its highly efficient membrane translocation (Lai et al., 2013). Recently, it has been described the neuroprotective 
effect of TAT-14-3-3e fusion protein against brain ischemic injury through inhibiting neuronal apoptosis and autophagic activation (Zhu et al., 2014). The SynB peptides are a family of CPPs that show charge-mediated BBB selectivity, with uptake proceeding via a caveolaeindependent pathway (Lalatsa et al. , 2014). SynB peptides have been used as a cationic CPPs for low molecular weight actives and for peptides suchs as dalargin (Lalatsa et al. , 2014). Penetratin, a CPP with a low content of basic amino acids, has been used to functionalize PEG-PLA nanoparticles, and enhance the cellular accumulation (Lalatsa et al. , 2014).

Mastoparan is a 14- residue peptide from wasp venom and has been used in the construction of 21 residue peptide Transportan 10 (TP10) which delivers its cargo into the cells (Sharma et al., 2013).

Other kind of fusion proteins have been developed, such as the fusion of the neurotrophin glial cell line-derived neurotrophic factor (GDNF) and the antiinflammatory agent type II tumor necrosis factor receptor (TNFR) decoy receptor with the heavy chain of a chimeric monoclonal antibody (MAb) against the mouse transferrin receptor (TfR). These fusion proteins enhance the therapeutic effect of both compounds in an acute stroke situation (Sumbria et al., 2013).

\subsubsection{Drug delivery through microspheres and biodegradable wafers}

Microsphere technology has recently been implemented by using lipid-based polymeric devices to increase drug retention in the brain (Dang et al, 1994). The active water-soluble macromolecule agent is conjugated and loaded into tiny spheres that can be inserted into the brain through stereotaxic surgery (Batycky et al, 1997). This method is easier and safer than the methods exposed before since there is no need for open surgery and less damage is done around the implemented area. 
Biodegradable wafers are also being studied for the local delivery of drugs into the brain. An example of biodegradable polymer is the polyanhydride poly[bis](pcarboxyphenoxy) propane:sebacic acid] (PCCP:SA) (Leong et al, 1985), which offers a controlled drug release through polymer degradation. Adequate modifications in polymer composition and proportion can offer a range of delivery from days to years (Patel et al, 2009). The main drawback of this method is that some drugs have limited diffusion in brain parenchyma, which implies that the drug-polymer complex must be administered near the target.

\subsubsection{Alternative methods}

\subsubsection{Intranasal administration}

Intranasal administration is an alternative non-invasive method to deliver drugs to the CNS. Therapeutically active compounds are absorbed via sensorial neurons located in the olfactory bulb and delivered to the CNS through the CSF of the olfactory region. Clinical trials in humans have demonstrated this method viable and concluded that cerebral drug diffusion is done intraneuronally and/or extraneuronally (Illum, 2000). Small lipid soluble molecules have been assessed as in AD treatment with BDNF, achieving successful delivery (Thorne et al, 1995). Drug uptake through this pathway depends much on the molecular mass of the drug and is proportional to the drug lipophilicity (Thorne and Frey, 2001). However, there are many physiological variables that may condition the administration such as higher $\mathrm{pH}$, high enzymatic activity of the epithelium, mucosal irritation or even nasal pathologies such as a simple cold (Patel et al, 2009). Recently there are some studies which try to facilitate the brain delivery of the intranasal nano-sized micelles modifying them with TAT peptide in brain tumours (Taki et al, 2012). 
The advantages that this pathway offers are that it is a non-invasive technique and drugs are able to bypass the first-pass metabolism. Since this method is limited by drug's lipophobicity colloidal nanocarriers can be implemented to mask hydrophilic molecules and offer a wider range of molecules to be used in CNS disorders treatment (Tiwari and Amiji, 2006).

\subsubsection{Molecular Trojan Horses}

Molecular Trojan horses (TH) are vectors that are able to bind specifically receptors and they are attached to drugs which do not accept chemical modifications allowing them to cross $\mathrm{BBB}$. The complex TH-drug is called a chimeric peptide because of its mixed structure and double functionality, targeted transport $(\mathrm{TH})$ and pharmacological activity (drug). In this way drugs that do not tolerate chemical modifications can be systemically administered and correctly delivered to the brain since the vector-receptor is specific and once at position it is transported across the BBB. One of the most studied targets for TH-drug method is the insulin receptor due to its ubiquity in brain vessels (Vlieghe and Khrestchatisky, 2012).

\subsubsection{Genetic engineering}

Implanting inside the brain a living tissue that expresses and secretes the therapeutic molecule has been tested, and positive results were obtained in PD treatment (Madrid et al, 1991). Recently, neural stem cells (NSC) were implanted into the hippocampus of an Alzheimer's disease and Down syndrome model mice to change the levels of tau/reelin-positive granules (Kern et al., 2011). Another exemple is the neurotransplantation in mice nucleus accumbens of stem cells which expressed the human dopamine receptor to modify alcohol consumption (Grammatopoulos et al., 
2010). However, implanted cells do not survive unlimitedly since there is no revascularization around the tissue. Promising solutions from genetic engineering were assessed in order to obtain different cell types that secrete the desired agent with a longer survival rate, such as the co-grafting engineered neurotrophic factor-producing cells with engineered therapeutic agent producing cells (Leigh et al, 1994). More recently another study tried to solve that problem doing a co-transplantation with helper cells to offer trophic support (Liang et al., 2013).

\subsubsection{Liposomes, nanopolimers, nanoparticles and solid lipid nanoparticles}

Liposomes, nanopolimers, nanoparticles and solid lipid nanoparticles are carriers that can be administrated parenterally facilitating the delivery of drugs to the brain.

\subsection{Liposomes}

Liposomes (LP) are lipid bilayer-based artificial vesicle that imitates biological membrane with different size, 20 to $5000 \mathrm{~nm}$, and number of lipid bilayers, being unilamelar or multilamelar (Lasic, 1998) (Fig. 6). By using cholesterol and phosphatidylcoline they offer an internal hydrophilic environment that can facilitate the drug delivery across BBB. LP-encapsulated drugs have a lower volume of distribution compared to free drugs due to their inclusion in the liposomes but its guarantees its entry in brain. Cholesterol and high-phase transition lipid are added into the formulation to stabilize the lipid bilayer and provide a non-leaky transport system (Drummond et al, 1999).

Since LPs are highly lipophilic they are rapidly eliminated from circulation by the macrophages from reticuloendothelial system (RES) predominantly form liver and spleen (Drummond et al, 1999; Frank, 1993). In order to avoid the RES and to increase 
bioavailability they usually undergo surface modification with polyethylene glycol (PEG) to diminish their lipophilicity (Ricci et al, 2006). Many modifications are possibly done on the LPs due to their similar nature to the cellular membranes. Specific active targeting can be achieved by attaching mAbs to the liposomal surface (Zhang et al, 2004). The recognition by a receptor in the BBB promotes the internalization as a molecular TH. Other modification to improve the crossing of the BBB is the covalent conjugation of the cell-penetrating peptide TAT (AYGRKKRRQRRR) to the cholesterol part of liposomes, for exemple in the treatment of brain glioma animals (Qin et al., 2011). They have been tested even for genetic therapy (Craparo et al, 2011).

\subsection{Nanopolimers and nanoparticles}

Nanoscale delivery systems are increasing their importance because they offer a relatively drug nature-independent transport due to their ability to mask the physicochemical properties of the content (Vlieghe and Khrestchatisky, 2012). Generally, nanotechnology-based drugs delivery is found in oral, topical and injected formulation to take advantage of current administration methods. The main pathway in which the subsequent delivery systems overcome the BBB is mainly by BCECs uptake employing adsorptive-mediated endocytosis (De Jong and Borm, 2008).

Colloidal carriers, nanocarriers and nanovectors are polymer-based delivery system in which their main characteristic is their size that ranges from 10 to $1000 \mathrm{~nm}$. Beside their reduced size, a considerable volume of single or various compounds can be contained in them, uptaken by BCECs and reach the CNS (Brasnjevic et al, 2009). Currently, many biotechnological and pharmaceutical companies have approved nanotechnology-based delivery systems but only a few efficient drug-loading methods exist making it the principal limiting factor prior commercialization (Vlieghe and 
Khrestchatisky, 2012). The last step of the delivery process is drug release and is as crucial as the BBB crossing itself. These nanoscaled transport system also intend to improve drugs bioavailability and pharmacokinetics, thus meliorate the therapeutic index and safety profile. They generally offer a sustained release and constant levels of drug in plasma over the time. Several non-excluding mechanisms are available depending on the nature of the nanocarrier and the timing wanted for the drug, which are: drug desorption, drug diffusion from the container and polymeric matrix erosion (Jain, 2007).

Polymer-based nanocarriers are macromolecules formed by of multiple repetitions of single structural units that groups dendrimers and polymeric micelles (Vlieghe and Khrestchatisky, 2012). The former usually have a size under 50nm and have a branched organization consisting of multiple ramifications coming out from a central core (Wu et al, 2006). Branch terminations conforms the dendrimeric surface while internally the spaces between the branches are filled to drugs, radionuclides or agents used in image analysis. Once across the BBB a physiological and controlled degradation of the polymer releases the compounds in the brain parenchyma (Vlieghe and Khrestchatisky, 2012).

As for the latter, "biocompatible amphiphilic block copolymers" is the structural unit that constitute it, forming a rounded-shape consisting of a core and a shell with a size range from $50 \mathrm{~nm}$ to $100 \mathrm{~nm}$. These polymeric micelles have a hydrophobic internal core that contains the desired compound to be delivered surrounded by a hydrophilic shell (Olivier, 2005). These micelles are spontaneously formed in aqueous solution when a critical micelle concentration is achieved.

Nanoparticles (NPs) delivery system is solid colloidal particles with dimensions within the nanometric scale (Olivier, 2005; Orthmann et al, 2011). Similar to polymeric 
nanocarriers it is a macromolecule build up by repetitions of simple structural units consisting of biocompatible and GRAS ingredients. An advantage to LPs is their increased stability but they are also conditioned by its composition and by temperature, $\mathrm{pH}$, electrolyte composition, size and steric hydrance (Kreuter, 1994).

In nanoparticulate systems drugs are loaded by dissolution, capture, encapsulation, absorption or covalently conjugated (Avgoustakis, 2004). In compare with LPs, NPs require less excipients providing an easier formulation process and in terms of pharmacokinetic parameters they have higher stability and permits a more controlled drug release (Vlieghe and Khrestchatisky, 2012). Two types of NPs are mainly used nowadays: nanocapsules and nanospheres (Patel et al, 2009). The former has a core shell structure where the drug is contained inside while the latter has a continuous matrix structure where the drug is dissolved. The common nomenclature used in literature to designate both systems is NP since not always the difference is clear enough.

Some of the compounds already approved by the FDA are poly(glycolic acid) (PGA), poly(lactic acid) (PLA) and its copolymers poly(lactic-co-glycolic acid) (PLGA) (Brasnjevic et al, 2009). Biological polymers are also used in NP fabrication to prevent toxicity issues associated to synthetic polymers. A commonly used, if no the most, poly(butyl)cyanoacrylate (PBCA) polymer-based NPs has been used to deliver antineoplastic drugs, peptides and analgesics to the CNS, either by adsorption to surface or incorporation. The characteristic that differentiates it from other is its rapid biodegradability. The outcome of these PBCA NPs was favourable (Kreuter et al, 2002). Other compounds used are poly(alkylcyanoacrylates) (PACAs) that includes poly(butylcyanoacrylate) (PBCA) and poly(hexylcyanoacrylate) (PHCA, 
poly(methylidene malonate), poly(methyl)methacrylate (PMMA), acrylic copolymers and polyesters (Vlieghe and Khrestchatisky, 2012).

As in LPs, the surface of the NP can be modified chemically or biochemically with functional groups (PEG) or mAbs to target specific types of cells or tissues in order to improve bioavailability, to increase diffusion and even to protect it from enzymatic inactivation (Brigger et al, 2002). Other strategy is conjugate the nanoparticles to TAT to enhance the CNS bioavailability of the encapsulated drug (Rao et al., 2008). In fact, there are also olymeric micelles anchored with TAT for delivery of antibiotics across BBB (Liu et al., 2008). Many studies have been published about NPs and how subtle modifications can make a difference in the delivery.

\subsection{Solid lipid nanoparticles}

Solid lipid nanoparticles (SLN) are generally not classified as LPs and neither as NP although its lipidic nature (Montenegro et al, 2012). Structurally, SLNs are solid lipid based as the ones used in the food industry and are stabilized with common emulsifiers such as polysorbates, polxamers and bile salts. They are a novel drug delivery system developed to solve issues attending polymeric NPs. Although it maintains properties such as controlled drug release, increased drug stability and the success of overcoming different administration routes (eyes, topic, oral and parenteral). Since they are lipid-based they present a lower cytotoxicity, an easier preparation protocol and have an improved stability and drug release (Blasi et al, 2007; Denora et al, 2009). Brain-targeted SLN have been developed by coating the surface with thiamine that increased the unidirectional uptake transfer constant to the $\mathrm{BBB}$ at diferent brain perfusion intervals. It has been shown a great potential in the treatment of brain diseases such as cerebral malaria the SLNs conjugated with transferrin (Craparo et al., 2011). 


\subsection{Elimination and clearance of LP, NP and SNP}

LP and NP and generally all compounds that have a highly lipophilic are rapidly eliminated from the bloodstream or accumulated in different organs such as liver (6090\%), lungs (3-20\%), spleen (2-10\%) and bone marrow $(<1 \%)$ (Kreuter, 1994). Removal of the nanocarriers is mediated by conjugation to plasma proteins or opsonisation. Recognition and sequestration by Kupffer cells in the liver and macrophages of the RES limits their half-lives to 2-3min if no modification is made (Bazile et al, 1992). The elimination process consists of an initial opsonisation followed by a rapid uptake done by the mononuclear phagocytic system. However, RES behaviour depends much on physicochemical properties of the transporting molecule such as size and surface properties including hydrophobicity and charge (Denora et al, 2009). In order to impair the rapid elimination of LP, NP and SLN there are different strategies which consist in chemical modifications mainly cationization and PEGylation.

\subsection{Targeted drug delivery}

An efficient drug targeted delivery can reduce considerably the dose of drug needed and in consequence improve the safety in vivo, which is the major point in drug's commercialization. The strategy consists of attaching ligands that are specifically recognized by BCECs receptors such as sugar residues, folic acid or even engineered mAbs (Lockman et al, 2002; Mishra et al, 2006). Targeting moieties can be attached directly on the surface of the carrier system or on the external end of the PEG if it is PEGylated, forming what is known as third generation carriers (Vlieghe and Khrestchatisky, 2012). 
Each nanotechnology-based delivery systems can also be subclassified into first, second or third generation depending strictly on their surface modifications. LPs, NPs and SLNs that has not undergone any surface modifications are considered the first generation. If they do present modifications such as PEGylation or other stabilizing methods to reduce plasmatic clearance then they are known as second generation or also named stealth carrier. The latter denomination surges from the ability of modifications such as PEGylation that permits the delivery system to evade macrophages of the RES. At last, third generation or targeted sterically stabilized delivery systems apart from improved PK from the second generation can also target specific organs or cell-types.

Preclinical data in brain cancer models indicate that PEGylated liposomal doxorubicin with an additional glutathione (GSH) coating can significantly reduce brain tumor growth (Gaillard 2011). Other strategy could be the design of glucosyl liposome ligands, which are able to cross BBB by GLUT1 as drug carriers in targeting delivery system (Qu et al., 2014). Glucosyl modified liposomes showed potential application with brain targeting, high transfer efficiency, good in vivo cycling stability and easy preparation (Qu et al., 2014). Surface modification of liposomes with CPPs facilitates endosomal escape and increases their cellular delivery (Sharma et al., 2013). There are studies combining CPPs with Transferrin (Tf)-liposomes which result in biocompatible formulations leading to efficient translocation of doxorubicina across cellular and brain endothelial barriers both in vitro and in vivo (Sharma et al., 2013).

Lactoferrin (Lf), a single-chain iron-binding glycoprotein, is part of Tf family which can penetrate the BBB via receptor-mediated transcytosis (Huang et al., 2013). Some studies developed a doxorubicin-loaded lactoferrin-modified procationic liposome delivery system and evaluated its therapeutic effect for glioma (Chen et al., 2011). Other studies focused on developing dual-targeting daunorubicin PEG-liposomes 
by conjugating vesicles with p-aminophenyla- D-manno-pyranoside (MAN) and transferrin (TF) (Ying et al., 2010; Lai et al., 2013). The ligand MAN plays a major role in transporting the liposomes across the $\mathrm{BBB}$ while $\mathrm{TF}$ acts as a main role in targeting brain glioma cells (Lai et al., 2013).

Although the main aim of targeted LPs and NPs is to offer an organ-specific uptake many efforts have gone beyond and conferred drug carriers the ability to aim an additional target once inside the CNS. The secondary target is achieved by 3 strategies: dual targeting, sequential targeting and selective action targeting. The first, dual targeting approach employs a single targeting moiety that has its receptor expressed at the $\mathrm{BBB}$ and at the desired site of action. Secondly, sequential targeting exerts its function through the combination of two targeting ligands. The first one directs the compound to the brain while the other one is the responsible for cell specificity inside the brain. At last, selective action targeting is used to achieve cell-type specificity. This targeting method shares common features with the pro-drug approach. The delivered drug, once reach the brain is not active until a cell-type specific enzyme cleaves and releases the drug. Since the enzymes are restricted to a certain subpopulation of cells only these cells will be under the effect of the therapeutic compound (Zhang et al, 2002).

In addition, nanoparticulate vectors of drugs also can be chemically modified to increase cellular uptake and the potential delivery in different cell compartments (Juillerat-Jeanneret 2008). Anti-cancer agents have been loaded in nanocontainers conjugated with ligands targeting the BBB to enhance selectivity for brain cancers (Soni et al. 2005).

\section{Conclusions}


$\mathrm{BBB}$ is a highly organized structure where the microenvironment created by the contact between ECs, astrocytes, pericytes and neurons confers the special characteristics to the BBB. A plethora of proteins are involved in the maintenance of the impermeability to the systemic circulation allowing the crossing to specific molecules in a regulated ratio. But the current challenge for the neurological treatments of age associated diseases, cancer or other CNS pathologies is the delivery of drugs crossing the $\mathrm{BBB}$ addressing their cellular targets inside the brain. It has to be considered that despite the great effort to develop efficient targeting and delivery systems, many other limitations must be addressed. Efficient brain targeting to brain receptors may not necessarily deliver the drugs across the $\mathrm{BBB}$ and inside does not ensure correct parenchymal diffusion not to mention a possible trigger of immunological responses. Nowadays different approaches are been developed using classical pharmacology and nanotechnology to achieve it and there are successful results to presume that soon there will be a new generation of drugs delivery system working properly.

\section{Acknowledgements}

This work was supported by the Plan Estatal de I+D+i 2013-2016 and the ISCIII-Subdirección General de Evaluación y Fomento de la Investigación (Grants PI13/00408, PI08/00574 and Red HERACLES RD12/0042/0014 \& RD12/0042/0016) and FEDER Funds; Spanish Ministry of Science and Innovation (RD12/0042/0016; BIO2011-25039); Generalitat de Catalunya (SGR09-1369 and SGR-760); and Fundació la Marató de TV3 (100310).

Declaration of interest: The authors report no conflicts of interest. The authors alone are responsible for the content and writing of the paper. 


\section{References}

Abbott NJ. (2002). Astrocyte-endothelial interactions and blood-brain barrier permeability. J Anat, 200, 629-38.

Abbott NJ, Romero IA. (1996). Transporting therapeutics across the blood-brain barrier. Mol Med Today, 2, 106-13.

Abbott NJ, Ronnback L, Hansson E. (2006). Astrocyte-endothelial interactions at the blood-brain barrier. Nat Rev Neurosci, 7, 41-53.

Adams S, Brown H, Turner G. (2002). Breaking down the blood-brain barrier: signaling a path to cerebral malaria? Trends in parasitology, 18, 360-66.

Aono S, Nakagawa S, Reynolds AB, Takeichi M. (1999). p120(ctn) acts as an inhibitory regulator of cadherin function in colon carcinoma cells. J Cell Biol, $145,551-62$.

Avgoustakis K. (2004). Pegylated poly(lactide) and poly(lactide-co-glycolide) nanoparticles: preparation, properties and possible applications in drug delivery. Curr Drug Deliv, 1, 321-33.

Balda MS, Flores-Maldonado C, Cereijido M, Matter K. (2000). Multiple domains of occludin are involved in the regulation of paracellular permeability. $J$ Cell Biochem, 78, 85-96.

Bartus RT, Snodgrass P, Marsh J, Agostino M, Perkins A, Emerich DF. (2000). Intravenous cereport (RMP-7) modifies topographic uptake profile of carboplatin within rat glioma and brain surrounding tumor, elevates platinum levels, and enhances survival. J Pharmacol Exp Ther, 293, 903-11.

Batycky RP, Hanes J, Langer R, Edwards DA. (1997). A theoretical model of erosion and macromolecular drug release from biodegrading microspheres. J Pharm Sci, 86, 1464-77. 
Bazile DV, Ropert C, Huve P, Verrecchia T, Marlard M, Frydman A, Veillard M, Spenlehauer G. (1992). Body distribution of fully biodegradable [14C]poly(lactic acid) nanoparticles coated with albumin after parenteral administration to rats. Biomaterials, 13, 1093-102.

Bazzoni G. (2006). Endothelial tight junctions: permeable barriers of the vessel wall. Thromb Haemost, 95, 36-42.

Bazzoni G, Dejana E. (2004). Endothelial cell-to-cell junctions: molecular organization and role in vascular homeostasis. Physiol Rev, 84, 869-901.

Begley DJ. (2004). Delivery of therapeutic agents to the central nervous system: the problems and the possibilities. Pharmacol Ther, 104, 29-45.

Betz AL, Bowman PD, Goldstein GW. (1983). Hexose transport in microvascular endothelial cells cultured from bovine retina. Exp Eye Res, 36, 269-77.

Blasberg RG, Patlak C, Fenstermacher JD. (1975). Intrathecal chemotherapy: brain tissue profiles after ventriculocisternal perfusion. J Pharmacol Exp Ther, 195, $73-83$

Blasi P, Giovagnoli S, Schoubben A, Ricci M, Rossi C. (2007). Solid lipid nanoparticles for targeted brain drug delivery. Adv Drug Deliv Rev, 59, 454-77.

Booth R, Kim H. (2012). Characterization of a microfluidic in vitro model of the bloodbrain barrier (muBBB). Lab Chip, 12, 1784-92.

Brasnjevic I, Steinbusch HW, Schmitz C, Martinez-Martinez P. (2009). Delivery of peptide and protein drugs over the blood-brain barrier. Prog Neurobiol, 87, 21251.

Brigger I, Morizet J, Aubert G, Chacun H, Terrier-Lacombe MJ, Couvreur P, Vassal G. (2002). Poly(ethylene glycol)-coated hexadecylcyanoacrylate nanospheres 
display a combined effect for brain tumor targeting. J Pharmacol Exp Ther, 303, 928-36.

Brightman MW, Kadota Y. (1992). Nonpermeable and permeable vessels of the brain. NIDA Res Monogr, 120, 87-107.

Broadwell RD, Balin BJ, Salcman M. (1988). Transcytotic pathway for blood-borne protein through the blood-brain barrier. Proc Natl Acad Sci U S A, 85, 632-36.

Brown D, Stow JL. (1996). Protein trafficking and polarity in kidney epithelium: from cell biology to physiology. Physiol Rev, 76, 245-97.

Brown RC, Mark KS, Egleton RD, Davis TP. (2004). Protection against hypoxiainduced blood-brain barrier disruption: changes in intracellular calcium. Am J Physiol Cell Physiol, 286, C1045-52.

Brown RC, Morris AP, O'Neil RG. (2007). Tight junction protein expression and barrier properties of immortalized mouse brain microvessel endothelial cells. Brain Res, $1130,17-30$.

Burns AR, Bowden RA, MacDonell SD, Walker DC, Odebunmi TO, Donnachie EM, Simon SI, Entman ML, Smith CW. (2000). Analysis of tight junctions during neutrophil transendothelial migration. J Cell Sci, 113 , 45-57.

Burns AR, Walker DC, Brown ES, Thurmon LT, Bowden RA, Keese CR, Simon SI, Entman ML, Smith CW. (1997). Neutrophil transendothelial migration is independent of tight junctions and occurs preferentially at tricellular corners. $J$ Immunol, 159, 2893-903.

Butt AM, Jones HC, Abbott NJ. (1990). Electrical resistance across the blood-brain barrier in anaesthetized rats: a developmental study. $J$ Physiol, 429, 47-62.

Cancilla PA, eBault LE. (1983). Neutral amino acid transport properties of cerebral endothelial cells in vitro. J Neuropathol Exp Neurol, 42, 191-9. 
Couraud PO. (1998). Infiltration of inflammatory cells through brain endothelium. Pathol Biol (Paris), 46, 176-80.

Craparo EF, Bondi ML, Pitarresi G, Cavallaro G. (2011). Nanoparticulate systems for drug delivery and targeting to the central nervous system. CNS Neurosci Ther, $17,670-7$.

Cucullo L, Hossain M, Rapp E, Manders T, Marchi N, Janigro D. (2007). Development of a humanized in vitro blood-brain barrier model to screen for brain penetration of antiepileptic drugs. Epilepsia, 48, 505-16.

Chen H, Qin Y, Zhang Q, Jiang W, Tang L, Liu J, He Q. (2011). Lactoferrin modified doxorubicin-loaded procationic liposomes for the treatment of gliomas. Eur $J$ Pharm Sci, 44, 164-73.

Cho CW, Liu Y, Cobb WN, Henthorn TK, Lillehei K, Christians U, Ng KY. (2002). Ultrasound-induced mild hyperthermia as a novel approach to increase drug uptake in brain microvessel endothelial cells. Pharm Res, 19, 1123-29.

Dang W, Colvin OM, Brem H, Saltzman WM. (1994). Covalent coupling of methotrexate to dextran enhances the penetration of cytotoxicity into a tissuelike matrix. Cancer Res, 54, 1729-35.

De Jong WH, Borm PJ. (2008). Drug delivery and nanoparticles:applications and hazards. Int J Nanomedicine, 3, 133-49.

Dehouck MP, Meresse S, Delorme P, Fruchart JC, Cecchelli R. (1990). An easier, reproducible, and mass-production method to study the blood-brain barrier in vitro. J Neurochem, 54, 1798-801.

Denora N, Trapani A, Laquintana V, Lopedota A, Trapani G. (2009). Recent advances in medicinal chemistry and pharmaceutical technology--strategies for drug delivery to the brain. Curr Top Med Chem, 9, 182-96. 
Doolittle ND, Petrillo A, Bell S, Cummings P, Eriksen S. (1998). Blood-brain barrier disruption for the treatment of malignant brain tumors: The National Program. $J$ Neurosci Nurs, 30, 81-90.

Drummond DC, Meyer O, Hong K, Kirpotin DB, Papahadjopoulos D. (1999). Optimizing liposomes for delivery of chemotherapeutic agents to solid tumors. Pharmacol Rev, 51, 691-743.

Duffy KR, Pardridge WM. (1987). Blood-brain barrier transcytosis of insulin in developing rabbits. Brain Res, 420, 32-8.

Emerich DF, Dean RL, Marsh J, Pink M, Lafreniere D, Snodgrass P, Bartus RT. (2000). Intravenous cereport (RMP-7) enhances delivery of hydrophilic chemotherapeutics and increases survival in rats with metastatic tumors in the brain. Pharm Res, 17, 1212-19.

Engelhardt B, Sorokin L. (2009). The blood-brain and the blood-cerebrospinal fluid barriers: function and dysfunction. Semin Immunopathol, 31, 497-511.

Erdlenbruch B, Alipour M, Fricker G, Miller DS, Kugler W, Eibl H, Lakomek M. (2003). Alkylglycerol opening of the blood-brain barrier to small and large fluorescence markers in normal and C6 glioma-bearing rats and isolated rat brain capillaries. Br J Pharmacol, 140, 1201-10.

Ettmayer P, Amidon GL, Clement B, Testa B. (2004). Lessons learned from marketed and investigational prodrugs. J Med Chem, 47, 2393-404.

Farrell CL, Pardridge WM. (1991). Blood-brain barrier glucose transporter is asymmetrically distributed on brain capillary endothelial lumenal and ablumenal membranes: an electron microscopic immunogold study. Proc Natl Acad Sci U S A, 88, 5779-83. 
Frank MM. (1993). The reticuloendothelial system and bloodstream clearance. J Lab Clin Med, 122, 487-8.

Fricker G, Miller DS. (2004). Modulation of drug transporters at the blood-brain barrier. Pharmacology, 70, 169-76.

Furuse M, Sasaki H, Tsukita S. (1999). Manner of interaction of heterogeneous claudin species within and between tight junction strands. J Cell Biol, 147, 891-903.

Gaillard PJ. (2011). Case study: to- BBB's G-Technology, getting the best from drugdelivery research with industry-academia partnerships. Ther Deliv, 2, 1391-4.

Garberg P, Ball M, Borg N, Cecchelli R, Fenart L, Hurst RD, Lindmark T, Mabondzo A, Nilsson JE, Raub TJ et al. . (2005). In vitro models for the blood-brain barrier. Toxicol In Vitro, 19, 299-334.

Geldenhuys WJ, Allen DD, Bloomquist JR. (2012). Novel models for assessing bloodbrain barrier drug permeation. Expert Opin Drug Metab Toxicol, 8, 647-53.

Goeckeler ZM, Wysolmerski RB. (1995). Myosin light chain kinase-regulated endothelial cell contraction: the relationship between isometric tension, actin polymerization, and myosin phosphorylation. J Cell Biol, 130, 613-27.

Gonzalez-Mariscal L, Betanzos A, Avila-Flores A. (2000). MAGUK proteins: structure and role in the tight junction. Semin Cell Dev Biol, 11, 315-24.

Grammatopoulos TN, Jones SM, Yoshimura M, Hoover BR, Das M, Snyder EY, Larson GA, Zahniser NR, Tabakoff B, Zawada WM. (2010). Neurotrasplantation of stem cells genetically modified to express human dopamine transporter reduces alcohol consumption. Stem Cell Res Ther, 1, 36.

Grau GE, Piguet PF, Vassalli P, Lambert PH. (1989). Tumor-necrosis factor and other cytokines in cerebral malaria: experimental and clinical data. Immunological reviews, 112, 49-70. 
Greenwood J, Luthert PJ, Pratt OE, Lantos PL. (1988). Hyperosmolar opening of the blood-brain barrier in the energy-depleted rat brain. Part 1. Permeability studies. J Cereb Blood Flow Metab, 8, 9-15.

Gumbiner B. (1987). Structure, biochemistry, and assembly of epithelial tight junctions. Am J Physiol, 253, C749-58.

Haseloff RF, Blasig IE, Bauer HC, Bauer H. (2005). In search of the astrocytic factor(s) modulating blood-brain barrier functions in brain capillary endothelial cells in vitro. Cell Mol Neurobiol, 25, 25-39.

Hatzfeld M. (2005). The p120 family of cell adhesion molecules. Eur J Cell Biol, 84, 205-14.

Hawkins BT, Davis TP. (2005). The blood-brain barrier/neurovascular unit in health and disease. Pharmacol Rev, 57, 173-85.

Hayashi Y, Nomura M, Yamagishi S, Harada S, Yamashita J, Yamamoto H. (1997). Induction of various blood-brain barrier properties in non-neural endothelial cells by close apposition to co-cultured astrocytes. Glia, 19, 13-26.

Hellstrom M, Gerhardt H, Kalen M, Li X, Eriksson U, Wolburg H, Betsholtz C. (2001). Lack of pericytes leads to endothelial hyperplasia and abnormal vascular morphogenesis. J Cell Biol, 153, 543-53.

Hirase T, Staddon JM, Saitou M, Ando-Akatsuka Y, Itoh M, Furuse M, Fujimoto K, Tsukita S, Rubin LL. (1997). Occludin as a possible determinant of tight junction permeability in endothelial cells. J Cell Sci, $110,1603-13$.

Holly J, Perks C. (2006). The role of insulin-like growth factor binding proteins. Neuroendocrinology, 83, 154-60. 
Huang FY, Chen WJ, Lee WY, Lo ST, Lee TW, Lo JM. (2013). In vitro and in vivo evaluation of lactoferrin-conjugated liposomes as a novel carrier to improve the brain delivery. Int J Mol Sci, 14, 2862-74.

Hwang SR, Kim K. (2014). Nano-enabled delivery systems across the blood-brain barrier. Arch Pharm Res, 37, 24-30.

Igarashi Y, Utsumi H, Chiba H, Yamada-Sasamori Y, Tobioka H, Kamimura Y, Furuuchi K, Kokai Y, Nakagawa T, Mori M et al. . (1999). Glial cell linederived neurotrophic factor induces barrier function of endothelial cells forming the blood-brain barrier. Biochem Biophys Res Commun, 261, 108-12.

Illum L. (2000). Transport of drugs from the nasal cavity to the central nervous system. Eur J Pharm Sci, 11, 1-18.

Isobe I, Watanabe T, Yotsuyanagi T, Hazemoto N, Yamagata K, Ueki T, Nakanishi K, Asai K, Kato T. (1996). Astrocytic contributions to blood-brain barrier (BBB) formation by endothelial cells: a possible use of aortic endothelial cell for in vitro BBB model. Neurochem Int, 28, 523-33.

Jain KK. (2007). Use of nanoparticles for drug delivery in glioblastoma multiforme. Expert Rev Neurother, 7, 363-72.

Janzer RC, Raff MC. (1987). Astrocytes induce blood-brain barrier properties in endothelial cells. Nature, 325, 253-7.

Juillerat-Jeanneret L. (2008). The targeted delivery of cancer drugs across the bloodbrain barrier: chemical modifications of drugs or drug-nanoparticles? Drug Discov Today, 13, 1099-106.

Kacem K, Lacombe P, Seylaz J, Bonvento G. (1998). Structural organization of the perivascular astrocyte endfeet and their relationship with the endothelial glucose transporter: a confocal microscopy study. Glia, 23, 1-10. 
Kang YS, Pardridge WM. (1994). Brain delivery of biotin bound to a conjugate of neutral avidin and cationized human albumin. Pharm Res, 11, 1257-64.

Kern DS, Maclean KN, Jiang H, Synder EY, Sladek JR Jr, Bjugstad KB. (2011). Neural stem cells reduce hippocampal tau and reelin accumulation in aged Ts65Dn Down syndrome mice. Cell Transplant, 20, 371-9.

Kim GY, Tyler BM, Tupper MM, Karp JM, Langer RS, Brem H, Cima MJ. ( 2007). Resorbable polymer microchips releasing BCNU inhibit tumor growth in the rat 9L flank model. J Control Release, 123, 172-8.

Kreuter J. (1994). Drug targeting with nanoparticles. Eur J Drug Metab Pharmacokinet, $19,253-6$.

Kreuter J, Shamenkov D, Petrov V, Ramge P, Cychutek K, Koch-Brandt C, Alyautdin R. (2002). Apolipoprotein-mediated transport of nanoparticle-bound drugs across the blood-brain barrier. J Drug Target, 10, 317-25.

Kroll RA, Neuwelt EA. (1998). Outwitting the blood-brain barrier for therapeutic purposes: osmotic opening and other means. Neurosurgery, 42, 1083-99; discussion 1099-100.

Kutcher ME, Herman IM. (2009). The pericyte: cellular regulator of microvascular blood flow. Microvascular research, 77, 235-46.

Kwiatkowski D. (1990). Tumour necrosis factor, fever and fatality in falciparum malaria. Immunology letters, 25, 213-6.

Lai CH, Kuo KH. (2005). The critical component to establish in vitro BBB model: Pericyte. Brain research reviews, 50, 258-65.

Lai F, Fadda AM, Sinico C. (2013). Liposomes for brain delivery. Expert Opin Drug Deliv, 10, 1003-22. 
Lalatsa A, Schatzlein AG, Ucheqbu IF. (2014). Strategies to deliver peptide drugs to the brain. Mol Pharm, Epub ahead of print.

Lampugnani MG, Corada M, Andriopoulou P, Esser S, Risau W, Dejana E. (1997). Cell confluence regulates tyrosine phosphorylation of adherens junction components in endothelial cells. $J$ Cell Sci, $110,2065-77$.

Lampugnani MG, Corada M, Caveda L, Breviario F, Ayalon O, Geiger B, Dejana E. (1995). The molecular organization of endothelial cell to cell junctions: differential association of plakoglobin, beta-catenin, and alpha-catenin with vascular endothelial cadherin (VE-cadherin). J Cell Biol, 129, 203-17.

Lasic DD. (1998). Novel applications of liposomes. Trends Biotechnol, 16, 307-21.

Lee G, Dallas S, Hong M, Bendayan R. (2001). Drug transporters in the central nervous system: brain barriers and brain parenchyma considerations. Pharmacol Rev, 53, 569-96.

Lee KR, Kawai N, Kim S, Sagher O, Hoff JT. (1997). Mechanisms of edema formation after intracerebral hemorrhage: effects of thrombin on cerebral blood flow, blood-brain barrier permeability, and cell survival in a rat model. J Neurosurg, 86, 272-8.

Lee SW, Kim WJ, Choi YK, Song HS, Son MJ, Gelman IH, Kim YJ, Kim KW. (2003). SSeCKS regulates angiogenesis and tight junction formation in blood-brain barrier. Nat Med, 9, 900-6.

Leigh K, Elisevich K, Rogers KA. (1994). Vascularization and microvascular permeability in solid versus cell-suspension embryonic neural grafts. $J$ Neurosurg, 81, 272-83. 
Leong KW, Brott BC, Langer R. (1985). Bioerodible polyanhydrides as drug-carrier matrices. I: Characterization, degradation, and release characteristics. J Biomed Mater Res, 19, 941-55.

Liang Y, Agren L, Lyczek A, Walczak P, Bulte JW. (2013). Neural progenitor cell survival in mouse brain can be improved by co-transplantation of helper cells expressing bFGF under doxycycline control. Exp Neurol, 247, 73-9.

Liu L, Venkatraman SS, Yang YY, Guo K, Lu J, He B, Moochhala S, Kan L. (2008). Polymeric micelles anchores with TAT for delivery of antibiotics across the blood-brain barrier. Biopolymers, 90, 617-23.

Lockman PR, Mumper RJ, Khan MA, Allen DD. (2002). Nanoparticle technology for drug delivery across the blood-brain barrier. Drug Dev Ind Pharm, 28, 1-13.

Loch-Neckel G, Koepp J. (2010). [The blood-brain barrier and drug delivery in the central nervous system]. Rev Neurol, 51, 165-74.

Loscher W, Potschka H. (2005). Role of drug efflux transporters in the brain for drug disposition and treatment of brain diseases. Prog Neurobiol, 76, 22-76.

Mackic JB, Weiss MH, Miao W, Kirkman E, Ghiso J, Calero M, Bading J, Frangione B, Zlokovic BV. (1998). Cerebrovascular accumulation and increased blood-brain barrier permeability to circulating Alzheimer's amyloid beta peptide in aged squirrel monkey with cerebral amyloid angiopathy. J Neurochem, 70, 210-5.

Madrid Y, Langer LF, Brem H, Langer R. (1991). New directions in the delivery of drugs and other substances to the central nervous system. Adv Pharmacol, 22, 299-324.

Madsen SJ, Hirschberg H. (2010). Site-specific opening of the blood-brain barrier. $J$ Biophotonics, 3, 356-67. 
Maher PA, Pasquale EB. (1988). Tyrosine phosphorylated proteins in different tissues during chick embryo development. J Cell Biol, 106, 1747-55.

Mann GE, Yudilevich DL, Sobrevia L. (2003). Regulation of amino acid and glucose transporters in endothelial and smooth muscle cells. Physiol Rev, 83, 183-252.

Masi BC, Tyler BM, Bow H, Wicks RT, Xue Y, Brem H, Langer R, Cima MJ. (2012). Intracranial MEMS based temozolomide delivery in a 9L rat gliosarcoma model. Biomaterials, 33, 5768-75.

Matsukado K, Inamura T, Nakano S, Fukui M, Bartus RT, Black KL. (1996). Enhanced tumor uptake of carboplatin and survival in glioma-bearing rats by intracarotid infusion of bradykinin analog, RMP-7. Neurosurgery, 39, 125-33; discussion 133-34.

McAllister MS, Krizanac-Bengez L, Macchia F, Naftalin RJ, Pedley KC, Mayberg MR, Marroni M, Leaman S, Stanness KA, Janigro D. (2001). Mechanisms of glucose transport at the blood-brain barrier: an in vitro study. Brain Res, 904, 20-30.

McCrea PD, Gumbiner BM. (1991). Purification of a 92-kDa cytoplasmic protein tightly associated with the cell-cell adhesion molecule E-cadherin (uvomorulin). Characterization and extractability of the protein complex from the cell cytostructure. J Biol Chem, 266, 4514-20.

Mi H, Haeberle H, Barres BA. (2001). Induction of astrocyte differentiation by endothelial cells. J Neurosci, 21, 1538-47.

Miller G. (2002). Drug targeting. Breaking down barriers. Science, 297, 1116-8.

Mishra V, Mahor S, Rawat A, Gupta PN, Dubey P, Khatri K, Vyas SP. (2006). Targeted brain delivery of AZT via transferrin anchored pegylated albumin nanoparticles. J Drug Target, 14, 45-53. 
Mizuguchi H, Utoguchi N, Mayumi T. (1997). Preparation of glial extracellular matrix: a novel method to analyze glial-endothelial cell interaction. Brain Res Brain Res Protoc, 1, 339-43.

Montenegro L, Trapani A, Latrofa A, Puglisi G. (2012). In vitro evaluation on a model of blood brain barrier of idebenone-loaded solid lipid nanoparticles. $J$ Nanosci Nanotechnol, 12, 330-7.

Nagafuchi A, Takeichi M. (1989). Transmembrane control of cadherin-mediated cell adhesion: a $94 \mathrm{kDa}$ protein functionally associated with a specific region of the cytoplasmic domain of E-cadherin. Cell Regul, 1, 37-44.

Neuwelt EA. (2004). Mechanisms of disease: the blood-brain barrier. Neurosurgery, 54, 131-40; discussion 141-2.

Newton HB. (2006). Advances in strategies to improve drug delivery to brain tumors. Expert Rev Neurother, 6, 1495-509.

Olivier JC. (2005). Drug transport to brain with targeted nanoparticles. NeuroRx, 2, 108-19.

Orthmann A, Fichtner I, Zeisig R. (2011). Improving the transport of chemotherapeutic drugs across the blood-brain barrier. Expert Rev Clin Pharmacol, 4, 477-90.

Palmeri D, van Zante A, Huang CC, Hemmerich S, Rosen SD. (2000). Vascular endothelial junction-associated molecule, a novel member of the immunoglobulin superfamily, is localized to intercellular boundaries of endothelial cells. J Biol Chem, 275, 19139-45.

Pardridge WM. (1992). Recent developments in peptide drug delivery to the brain. Pharmacol Toxicol, 71, 3-10.

Pardridge WM. (1994). New approaches to drug delivery through the blood-brain barrier. Trends Biotechno, 12, 239-45. 
Pardridge WM, Oldendorf WH. (1975). Kinetic analysis of blood-brain barrier transport of amino acids. Biochim Biophys Acta, 401, 128-36.

Pardridge WM, Triguero D, Buciak J, Yang J. (1990). Evaluation of cationized rat albumin as a potential blood-brain barrier drug transport vector. J Pharmacol Exp Ther, 255, 893-9.

Patel MM, Goyal BR, Bhadada SV, Bhatt JS, Amin AF. (2009). Getting into the brain: approaches to enhance brain drug delivery. CNS Drugs, 23, 35-58.

Perry VH, Anthony DC, Bolton SJ, Brown HC. (1997). The blood-brain barrier and the inflammatory response. Mol Med Today, 3, 335-41.

Petty MA, Lo EH. (2002). Junctional complexes of the blood-brain barrier: permeability changes in neuroinflammation. Prog Neurobiol, 68, 311-23.

Polli EE. (2000). Transplanting bone-marrow stem cells in the central nervous system. Haematologica, 85, 1009-10.

Prieto P, Blaauboer BJ, de Boer AG, Boveri M, Cecchelli R, Clemedson C, Coecke S, Forsby A, Galla HJ, Garberg P et al. . (2004). Blood-brain barrier in vitro models and their application in toxicology. The report and recommendations of ECVAM Workshop 49. Altern Lab Anim, 32, 37-50.

Qin Y, Chen H, Yuan W, Kuai R, Zhang Q, Xie F, Zhang L, Zhang Z, Liu J, He Q. (2011). Liposome formulated with TAT-modified cholesterol for enhancing the brain delivery. Int J Pharm, 419, 85-95.

Qu B, Li X, Guan M, Li X, Hai L, Wu Y. (2014). Design, synthesis and biological evaluation of multivalent glucosides with high affinity as ligands for brain targeting liposomes. Eur J Med Chem, 72, 110-8. 
Rao KS, Reddy MK, Horning JL, Labhasetwar V. (2008). TAT- conjugated nanoparticles for the CNS delivery of anti-HIV drugs. Biomaterials, 29, 442938.

Ratcliffe MJ, Rubin LL, Staddon JM. 1997. Dephosphorylation of the cadherinassociated p100/p120 proteins in response to activation of protein kinase C in epithelial cells. J Biol Chem, 272, 31894-901.

Rautio J, Laine K, Gynther M, Savolainen J. (2008). Prodrug approaches for CNS delivery. Aaps J, 10, 92-102.

Reinhardt CA, Gloor SM. (1997). Co-culture blood-brain barrier models and their use for pharmatoxicological screening. Toxicol In Vitro, 11, 513-8.

Rempe R, Cramer S., Hüwel S, Galla HJ. (2011). Transport of Poly (n-butylcyanoacrylate) nanoparticles across the blood-brain barrier in vitro and their influence on barrier integrity. Biochem Biophys Res Commun, 406, 64-9.

Ricci M, Blasi P, Giovagnoli S, Rossi C. (2006). Delivering drugs to the central nervous system: a medicinal chemistry or a pharmaceutical technology issue? Curr Med Chem, 13, 1757-75.

Ridet JL, Malhotra SK, Privat A, Gage FH. (1997). Reactive astrocytes: cellular and molecular cues to biological function. Trends Neurosci, 20, 570-7.

Risau W, Wolburg H. (1990). Development of the blood-brain barrier. Trends Neurosci, $13,174-8$.

Rubin LL, Hall DE, Porter S, Barbu K, Cannon C, Horner HC, Janatpour M, Liaw CW, Manning K, Morales J et al. . (1991). A cell culture model of the blood-brain barrier. J Cell Biol, 115, 1725-35.

Rubin LL, Staddon JM. (1999). The cell biology of the blood-brain barrier. Annu Rev Neurosci, 22, 11-28. 
Salahuddin TS, Kalimo H, Johansson BB, Olsson Y. (1988). Observations on exsudation of fibronectin, fibrinogen and albumin in the brain after carotid infusion of hyperosmolar solutions. An immunohistochemical study in the rat indicating longlasting changes in the brain microenvironment and multifocal nerve cell injuries. Acta Neuropathol, 76, 1-10.

Santini JT, Jr., Cima MJ, Langer R. (1999). A controlled-release microchip. Nature, $397,335-8$.

Sarna GS, Bradbury MW, Cremer JE, Lai JC, Teal HM. (1979). Brain metabolism and specific transport at the blood-brain barrier after portocaval anastomosis in the rat. Brain Res, 160, 69-83.

Scheld WM. (1989). Drug delivery to the central nervous system: general principles and relevance to therapy for infections of the central nervous system. Rev Infect Dis, 11 Suppl 7:S1669-90.

Scherrmann JM. (2002). Drug delivery to brain via the blood-brain barrier. Vascul Pharmacol, 38, 349-54.

Schinkel AH. (1999). P-Glycoprotein, a gatekeeper in the blood-brain barrier. Adv Drug Deliv Rev, 36, 179-94.

Schinkel AH, Smit JJ, van Tellingen O, Beijnen JH, Wagenaar E, van Deemter L, Mol CA, van der Valk MA, Robanus-Maandag EC, te Riele HP et al. . (1994). Disruption of the mouse mdrla P-glycoprotein gene leads to a deficiency in the blood-brain barrier and to increased sensitivity to drugs. Cell, 77, 491-502.

Schinkel AH, Wagenaar E, Mol CA, van Deemter L. (1996). P-glycoprotein in the blood-brain barrier of mice influences the brain penetration and pharmacological activity of many drugs. J Clin Invest, 97, 2517-24. 
Schlageter KE, Molnar P, Lapin GD, Groothuis DR. (1999). Microvessel organization and structure in experimental brain tumors: microvessel populations with distinctive structural and functional properties. Microvasc Res, 58, 312-28.

Schroeter ML, Mertsch K, Giese H, Muller S, Sporbert A, Hickel B, Blasig IE. (1999). Astrocytes enhance radical defence in capillary endothelial cells constituting the blood-brain barrier. FEBS Lett, 449, 241-4.

Schulze C, Firth JA. (1993). Immunohistochemical localization of adherens junction components in blood-brain barrier microvessels of the rat. J Cell Sci, 104, 77382.

Sharma G, Modgil A, Zhong T, Sun C, Singh J. (2013). Influence of short-chain cellpenetrating peptides on transport of doxorubicin encapsulating receptor- targeted liposomes across brain endothelial barrier. Pharm Res, Epub ahead of print

Sobue K, Yamamoto N, Yoneda K, Hodgson ME, Yamashiro K, Tsuruoka N, Tsuda T, Katsuya H, Miura Y, Asai K et al. . (1999). Induction of blood-brain barrier properties in immortalized bovine brain endothelial cells by astrocytic factors. Neurosci Res, 35, 155-64.

Songjiang Z, Lixiang W. (2009). Amyloid-beta associated with chitosan nano-carrier has favorable immunogenicity and permeates the BBB. AAPS PharmSciTech, $10,900-5$.

Soni V, Kohli DV, Jain SK. (2005). Transferrin coupled liposomes as drug delivery carriers for brain targeting of 5- florouracil. J Drug Target, 13, 245-50.

Staddon JM, Rubin LL. (1996). Cell adhesion, cell junctions and the blood-brain barrier. Curr Opin Neurobiol, 6, 622-7. 
Stamatovic SM, Keep RF, Andjelkovic AV. (2008). Brain endothelial cell-cell junctions: how to "open" the blood brain barrier. Curr Neuropharmacol, 6, 17992.

Stanness KA, Westrum LE, Fornaciari E, Mascagni P, Nelson JA, Stenglein SG, Myers T, Janigro D. (1997). Morphological and functional characterization of an in vitro blood-brain barrier model. Brain Res, 771, 329-42.

Stewart PA, Wiley MJ. (1981). Developing nervous tissue induces formation of bloodbrain barrier characteristics in invading endothelial cells: a study using quail-chick transplantation chimeras. Dev Biol, 84, 183-92.

Sumbria RK, Boado RJj, Pardridge WM. (2013). Combination stroke therapy in the mouse with bloo-brain barrier penetrating IgG-GDNF and IgG-TNF decoy receptor fusion proteins. Brain Res, 1507, 91-6.

Sun H, Dai H, Shaik N, Elmquist WF. (2003). Drug efflux transporters in the CNS. Adv Drug Deliv Rev, 55, 83-105.

Taki H, Kanazawa T, Akiyama F, Takashima Y, Okada H. (2012). Intranasal delivery of camptothecin- loaded tat-modified nanomicells for treatment of intracranial brain tumors. Pharmaceuticals (Basel), 5, 1092-102.

Tamai I, Tsuji A. (2000). Transporter-mediated permeation of drugs across the bloodbrain barrier. J Pharm Sci, 89, 1371-88.

Thomas WE. (1999). Brain macrophages: on the role of pericytes and perivascular cells. Brain research reviews, 31, 42-57.

Thorne RG, Emory CR, Ala TA, Frey WH, 2nd. (1995). Quantitative analysis of the olfactory pathway for drug delivery to the brain. Brain Res, 692, 278-82. 
Thorne RG, Frey WH, 2nd. (2001). Delivery of neurotrophic factors to the central nervous system: pharmacokinetic considerations. Clin Pharmacokinet, 40, 90746.

Tiwari SB, Amiji MM. (2006). A review of nanocarrier-based CNS delivery systems. Curr Drug Deliv, 3, 219-32.

Treeratanapiboon L, Psathaki K, Wegener J, Looareesuwan S, Galla HJ, Udomsangpetch R. (2005). In vitro study of malaria parasite induced disruption of blood-brain barrier. Biochemical and biophysical research communications, $335,810-8$.

Verkman AS. (2002). Aquaporin water channels and endothelial cell function. J Anat, 200, 617-27.

Vlieghe P, Khrestchatisky M. (2012). Medicinal Chemistry Based Approaches and Nanotechnology-Based Systems to Improve CNS Drug Targeting and Delivery. Med Res Rev.

Vykhodtseva N, McDannold N, Hynynen K. (2008). Progress and problems in the application of focused ultrasound for blood-brain barrier disruption. Ultrasonics, 48, 279-96.

Williams LA, Martin-Padura I, Dejana E, Hogg N, Simmons DL. (1999). Identification and characterisation of human Junctional Adhesion Molecule (JAM). Mol Immunol, 36, 1175-88.

Witt KA, Gillespie TJ, Huber JD, Egleton RD, Davis TP. (2001). Peptide drug modifications to enhance bioavailability and blood-brain barrier permeability. Peptides, 22, 2329-43.

Wolburg H, Lippoldt A. (2002). Tight junctions of the blood-brain barrier: development, composition and regulation. Vascul Pharmacol, 38, 323-37. 
Wu G, Barth RF, Yang W, Kawabata S, Zhang L, Green-Church K. (2006). Targeted delivery of methotrexate to epidermal growth factor receptor-positive brain tumors by means of cetuximab (IMC-C225) dendrimer bioconjugates. Mol Cancer Ther, 5, 52-9.

Ying X, Wen H, Lu WL, Du J, Guo J, Tian W, Men Y, Zhang Y, Li RJ, Yang TY, Shang DW, Lou JN, Zhang LR, Zhang Q. (2010). Dual-targeting daunorubicin liposomes improve the therapeutic efficacy of brain glioma in animals. $J$ Control Release, 141, 183-92.

Zhang C, Su Z, Zhao B, Qu Q, Tan Y, Cai L, Li X. (2010). Tat-modified leptin is more accessible to hypothalamus through brain-blood barrier with a significant inhibition of body-weight gain in high-fat-diet fed mice. Exp Clin Endocrinol Diabetes, 118, 31-7.

Zhang Y, Zhang YF, Bryant J, Charles A, Boado RJ, Pardridge WM. (2004). Intravenous RNA interference gene therapy targeting the human epidermal growth factor receptor prolongs survival in intracranial brain cancer. Clin Cancer Res, 10, 3667-77.

Zhang Y, Zhu C, Pardridge WM. (2002). Antisense gene therapy of brain cancer with an artificial virus gene delivery system. Mol Ther, 6, 67-72.

Zhou QH, Lu JZ, Hui EK, Boado RJ, Pardridge WM. (2011). Delivery of a peptide radiopharmaceutical to brain with an IgG-avidin fusion protein. Bioconjug Chem, 22, 1611-8.

Zhu Y, Bu Q, Liu X, Hu W, Wang Y. (2014). Neuroprotective effect of TAT-14-3-3e fusion protein against cerebral ischemia/reperfusion injury in rats. PLoS One, 26, e93334 
Table 1. Tight junction proteins

\begin{tabular}{|c|c|c|c|}
\hline \multicolumn{2}{|c|}{ Protein } & Function & \multirow{2}{*}{\begin{tabular}{|l|} 
Reference \\
Furuse et al, 1999 \\
Heiskala et al, 2001
\end{tabular}} \\
\hline & Claudin & $\begin{array}{l}\text { Generation of the high electrical resistance avoiding free } \\
\text { access of ions through paracellular diffusion, to contribute to } \\
\text { the selective regulation across TJ }\end{array}$ & \\
\hline & Ocludin & $\begin{array}{l}\text { Maintenance of high resistance to allow the flux of non- } \\
\text { charged solutes and to contribute to the selective diffusion } \\
\text { regulation }\end{array}$ & $\begin{array}{l}\text { Balda et al, } 2000 \\
\text { Hirase et al,1997 } \\
\text { Nusrat et al, } 2005\end{array}$ \\
\hline & JAMs & Regulation of monocyte extravasation & $\begin{array}{l}\text { Palmeri et al, } 2000 \\
\text { Williams et al, } 1999\end{array}$ \\
\hline $\begin{array}{l}\text { PDF } \\
\text { motif }\end{array}$ & $\begin{array}{l}\text { MAGUK } \\
\text { (ZO-1, } 2 \text { and 3) }\end{array}$ & $\begin{array}{l}\text { Supporting and clustering many intracellular and cell surfaces } \\
\text { components in the TJs }\end{array}$ & $\begin{array}{l}\text { Gonzalez-Mariscal } \\
\text { et al, } 2000 \\
\text { Ponting et al, } 1997 \\
\text { Siegal et al, } 2000\end{array}$ \\
\hline $\begin{array}{l}\text { Non } \\
\text { PDF }\end{array}$ & Cingulin & $\begin{array}{l}\text { Cross-linker between TJ proteins and actin-myosin } \\
\text { cytoskeleton }\end{array}$ & $\begin{array}{l}\text { Citi and } \\
\text { Cordenonsi, } 1998 \\
\text { Cordenonsi et al, } \\
1999\end{array}$ \\
\hline motif & $7 \mathrm{H6}$ & Maduration and maintainance of TJs & Satoh et al, 1996 \\
\hline & ZONAB & Regulation of Erb transcription and paracellular permeability & $\begin{array}{l}\text { Balda et al, } 2000 \\
\text { Satoh et al, } 1996\end{array}$ \\
\hline & Rab13 & Participation in the polarized transport at TJ complex & $\begin{array}{l}\text { Stamatovic, } 2008 \\
\text { Tiwari and Imaji, } \\
2006\end{array}$ \\
\hline & PKC & $\begin{array}{l}\text { Involved in the regulation of polarization as well as in TJ } \\
\text { assembly }\end{array}$ & $\begin{array}{l}\text { Yamanaka et al, } \\
2001\end{array}$ \\
\hline & $\begin{array}{l}\text { Heterotrimeric } \\
\text { G protein }\end{array}$ & $\begin{array}{l}\mathrm{TJ} \text { assembly and maintainance the transendothelial electrical } \\
\text { resistance. }\end{array}$ & $\begin{array}{l}\text { Fukuhara et al, } 2003 \\
\text { Stamatovic et al, } \\
2008\end{array}$ \\
\hline \multicolumn{2}{|c|}{ Catenin (120 and p100) } & Regulation of TJ permeability. & Ratcliffe et al, 1997 \\
\hline
\end{tabular}




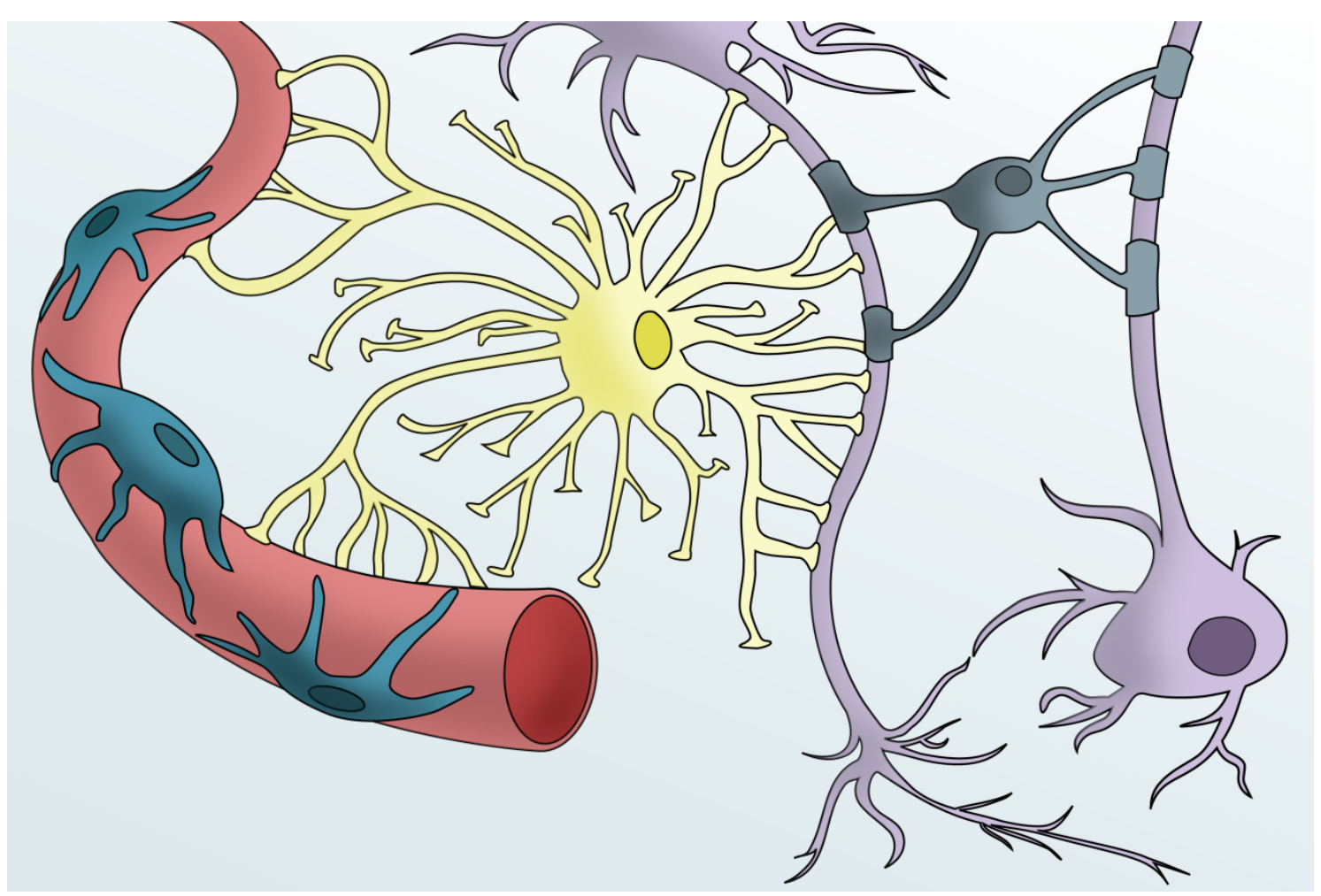

Figure 1. The BBB and the neurovascular unit. The blood brain barrier consist of a modified endothelium, which overexpresses tight junctions and adherens junctions, surrounded by pericytes, astrocytical processes and neurons. 


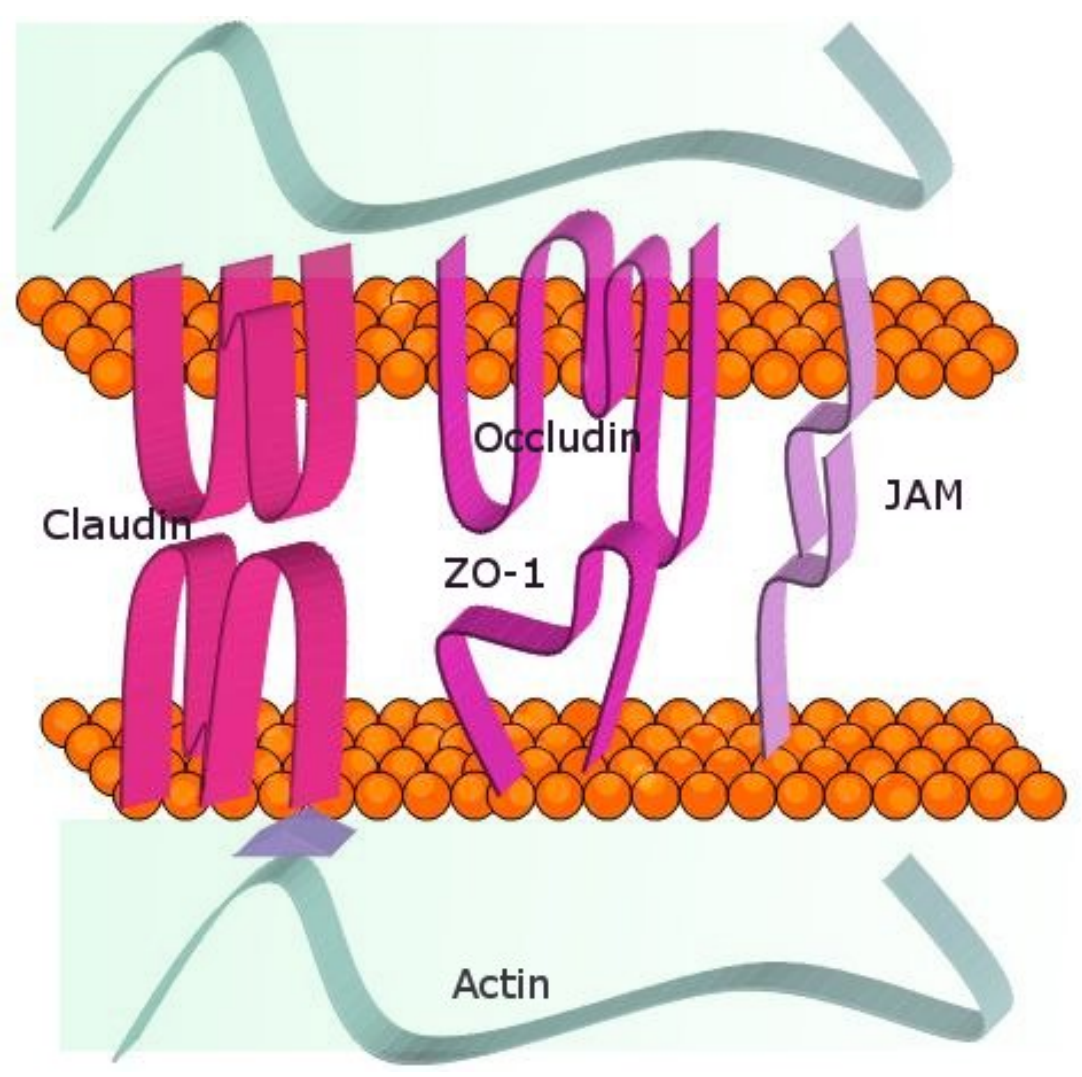

Figure 2. The tight junctions. Structure of the main proteins that form the tight junctions. They are proteins with extracellular domains that mediate physical interactions and intracellular proteins that anchors the former to the cytoskeleton. 

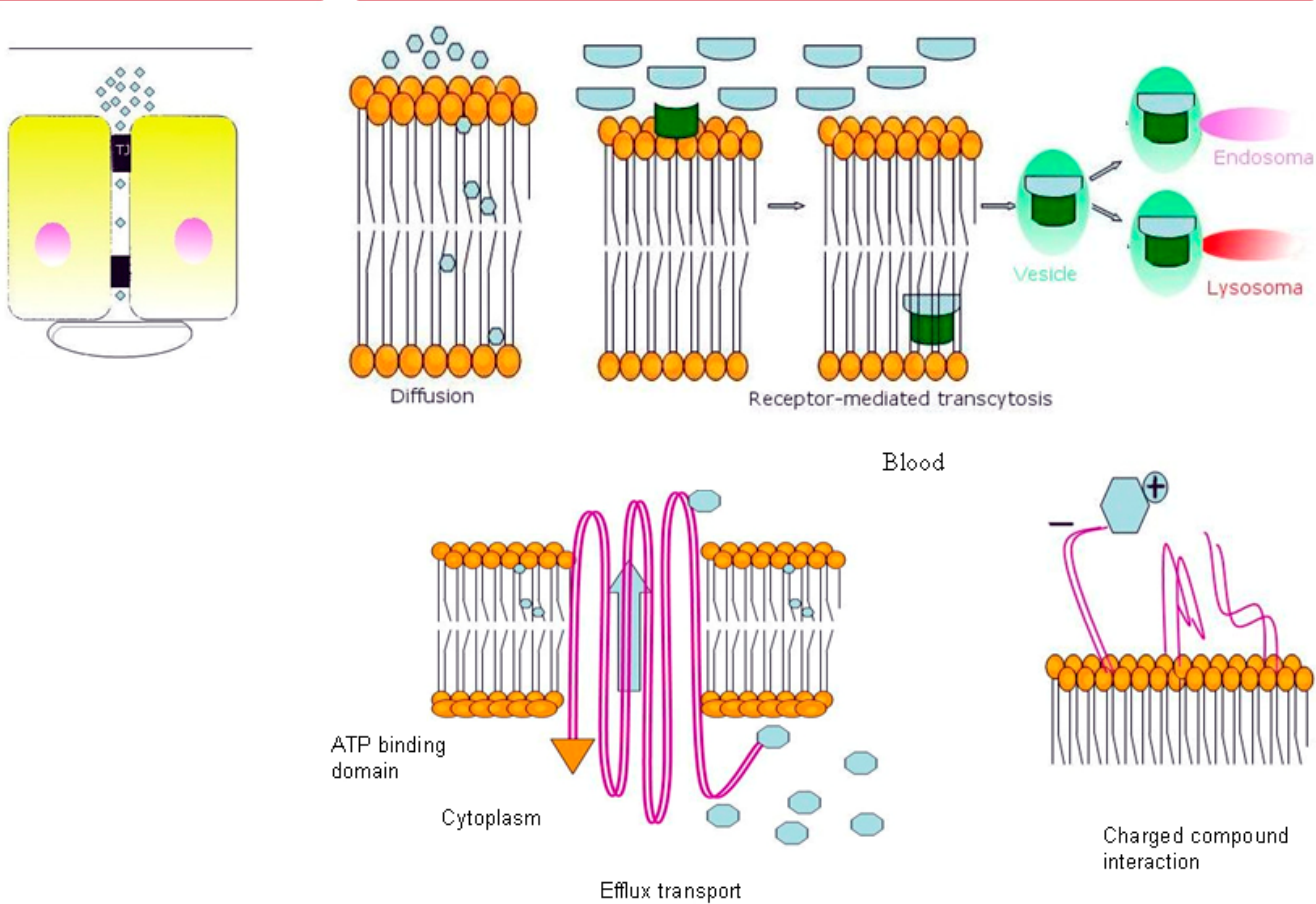

Figure 3. Physiological crossing of the BBB. Representation of the paracellular route and transcellular routes such as carrier-mediated endocytosis, efflux pumps, receptormediated endocytosis and adsorptive-mediated transcytosis. 


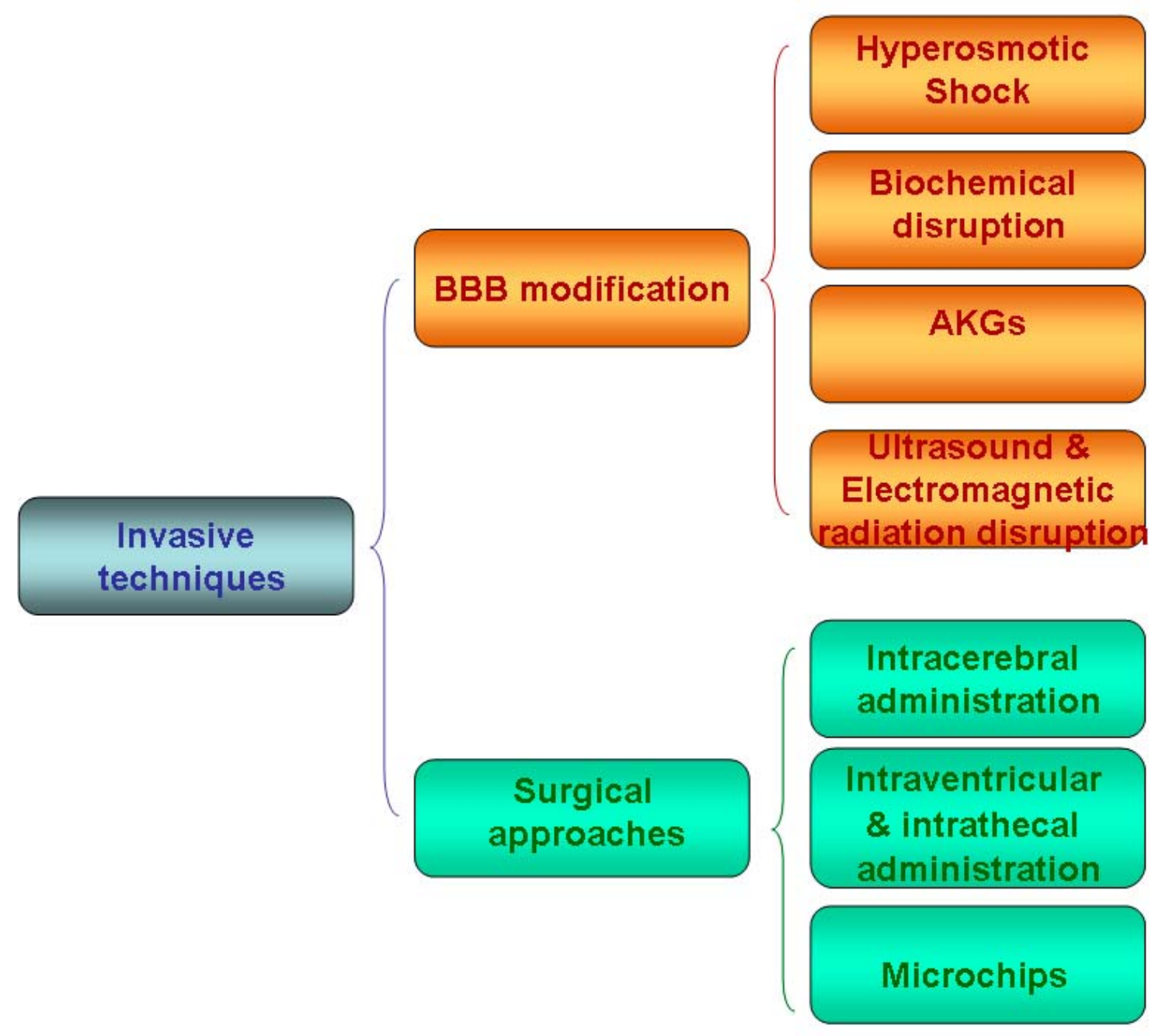

Figure 4. A schematic representation of current strategies to deliver drugs to the brain by invasive techniques. It encloses surgery-needed approaches and BBB disruption whilst non-invasive techniques include drug modification by medicinal chemistry approaches and drug encapsulation through nanotechnological carriers. 


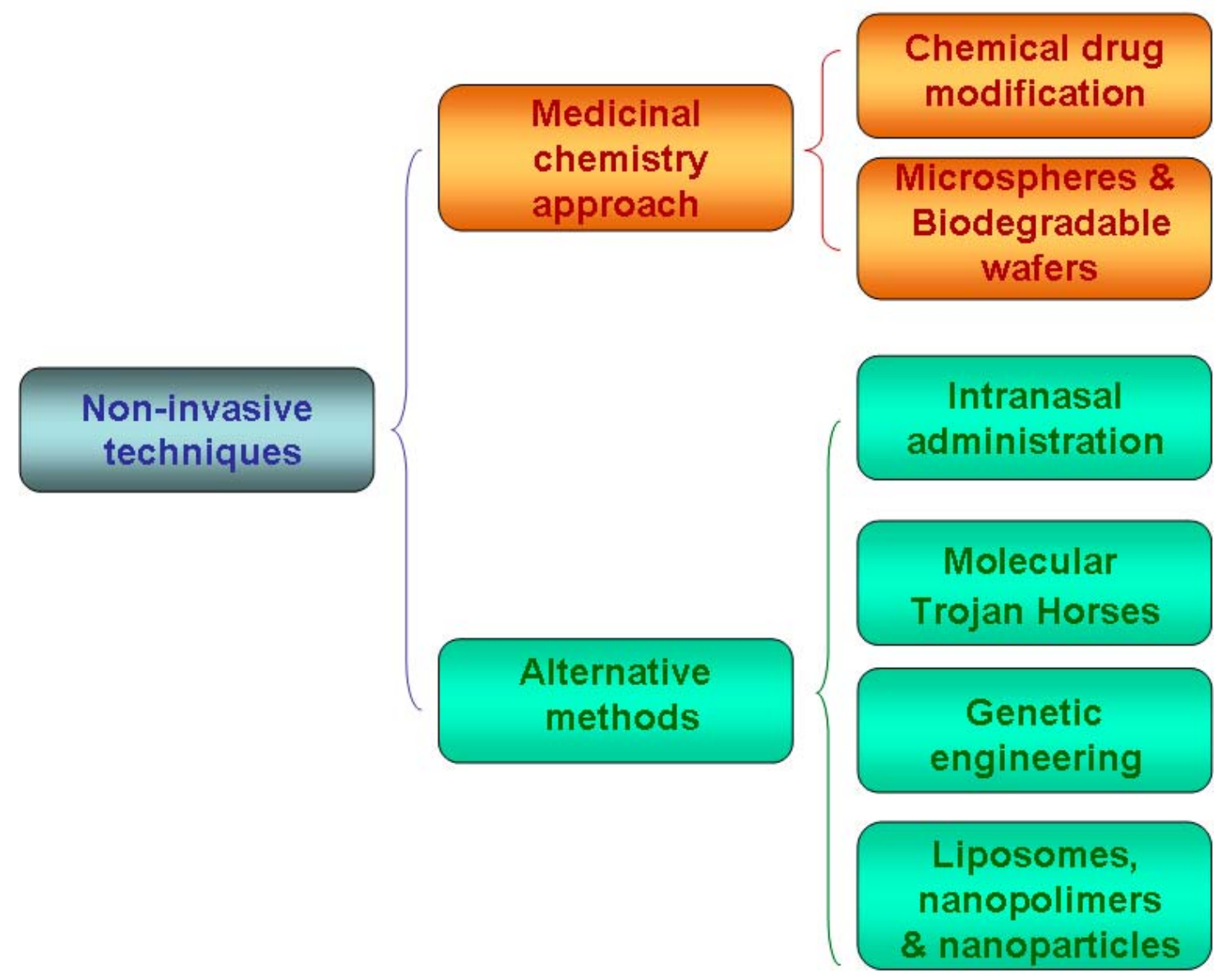

Figure 5. A schematic representation of current strategies to deliver drugs to the brain by non-invasive techniques. Non-invasive techniques include drug modification by medicinal chemistry approaches and drug encapsulation through nanotechnological carriers. 


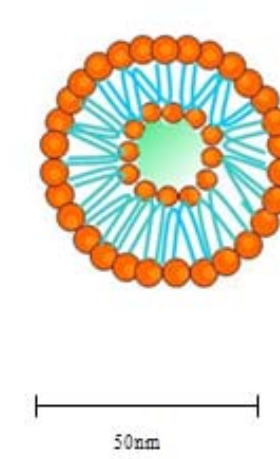

Small unillamelar vesicle

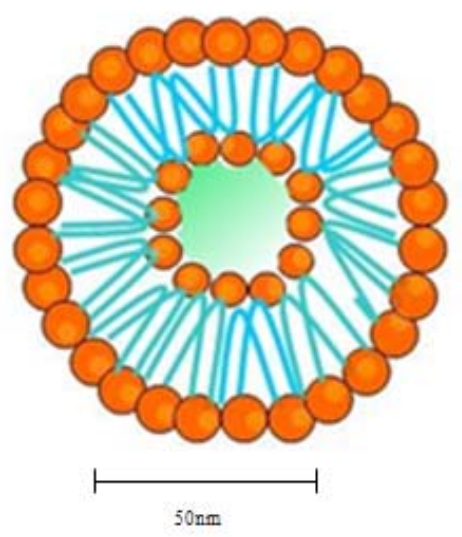

Large unillamelar vesicle

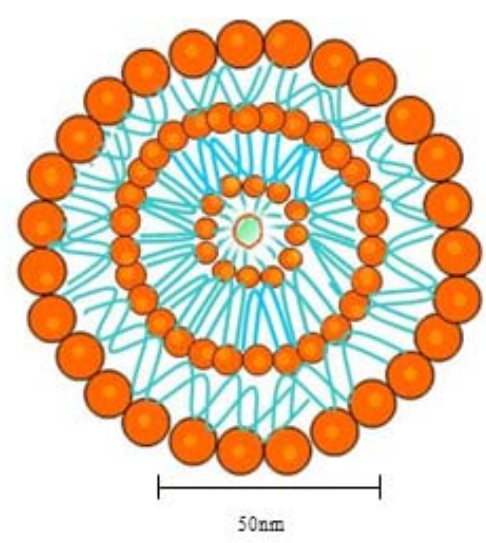

Multillamelar vesicle

Figure 6. Schematic representation of the three different types of lipososomes. Small Unilamelar Vesicles (SUV), Large Unilamelar Vesicles (LUV) and Multilamelar (MLV). 